\title{
RISK-BASED CAPITAL IN GENERAL INSURANCE
}

\author{
BY N. D. HOOKER, M.A., Ph.D., F.I.A., J. R. BUlMER, M.A., F.I.A., \\ S. M. COOPER, B.Sc., F.I.A., P. A. G. GREEN, B.A., F.I.A. \\ AND P. H. HINTON, B.A., F.I.A.
}

[Presented to the Institute of Actuaries, 27 November 1995]

\begin{abstract}
This paper looks at the problems of assessing, for solvency purposes, the capital requirements of a non-life insurer in the context of the United Kingdom. It considers how these capital requirements might vary according to the different risks to which an insurer is subject and how this Risk-Based Capital ( $\mathrm{RBC}$ ) might be measured in practice, using as a case study the $\mathrm{RBC}$ formula recently introduced in the United States of America. The paper also discusses the application of RBC concepts to the problem of internal capital allocation, to assist in measuring an insurer's rate of return to shareholders by business unit, as well as the more obvious regulatory application. The advantages and disadvantages of a formula-based approach to capital requirements for solvency purposes are discussed in comparison with possible alternative approaches to insurance supervision.
\end{abstract}

\section{KEYWORDS}

Capital; General Insurance; Insurance Supervision; Risk; Risk-Based Capital; Solvency

\section{INTRODUCTION}

\subsection{Preliminaries}

1.1.1 The paper looks at the problems of assessing, for solvency purposes, the capital requirements of a non-life insurer in the context of the United Kingdom. It considers how these capital requirements (or minimum required solvency margin) might vary according to the different risks to which an insurer is subject, and how this Risk-Based Capital (RBC) might be measured in practice.

1.1.2 The paper uses as a case study the RBC formula recently introduced in the United States of America. The proposals from Lloyd's for using RBC to assess members' capital requirements were exposed for comment as a consultation document too late for a thorough critique to be given in this paper.

1.1.3 The paper discusses some applications of $\mathrm{RBC}$, including capital allocation for measuring an insurer's rate of return to shareholders by business unit as well as the more obvious regulatory application. The advantages and disadvantages of a formula-based approach to capital requirements for solvency purposes are discussed in comparison with possible alternative approaches to insurance supervision.

1.1.4 The concept of RBC in life insurance has been considered by, for example, the Joint Actuarial Working Party (1993) and by Needleman \& Roff (1995). The scope of the present paper does not include life insurance or pension 
funds, but, although there are different issues involved, the authors believe that the same concepts should be considered, albeit with due regard to the context in which these businesses are controlled and managed, and to the framework within which the corresponding assets and liabilities are valued. In the remainder of this paper we consider only a pure non-life insurer.

1.1.5 This paper has developed out of the work of the General Insurance Study Group's working parties on Capital Requirements and Risk-Based Capital over the last three years, including a paper to the London Market Actuaries Group (Hooker, 1993), and papers to the GISG's Conventions in Hinckley Island and Glasgow (Hooker et al., 1993 and 1994). Some of the material in this paper has been adapted from these earlier papers. However, the authors feel that it is now appropriate to bring the issues to a wider actuarial audience.

1.1.6 RBC is a controversial subject, on which many diverging opinions are held. In this paper some of these opinions are presented and discussed, without necessarily being shared by the authors, or by any organisation with which they are, or have been, associated.

1.1.7 In discussing risk, many viewpoints could be adopted. In most sections we have adopted the policyholder's or regulator's viewpoint, in which the risk is that of the insurer becoming unable to meet its claims obligations in full. An alternative viewpoint is that of the providers of the insurer's capital. The risk from this viewpoint is that of under-performance of the investment of this capital. Consideration of these two viewpoints draws attention to the distinction between diversifiable and systematic risk: while shareholders can diversify their interests in insurers, policyholders generally cannot, and so regulators must presume that the insolvency risk is not diversifiable. Lewin et al. (1995) give a useful section, 'Some Thoughts on Risk', which describes both the distinction between diversifiable and systematic risk and the distinction between quantifiable and unquantifiable risk. These distinctions will be commented on in the later sections of the present paper.

\subsection{The History of RBC}

1.2.1 The early 1960s saw RBC concepts emerge in the banking industry. These came about first in Germany, spreading to other European countries, before being adopted by the Basle 'Group of 10' Committee on Banking Supervision in the middle-to-late 1980s. In the U.S.A., the 1990 Dingell report Failed Promises criticised the U.S. system of insurance regulation and proposed numerous changes to that system.

1.2.2 Partly in response to this report, with its proposals for a greater federal role in insurance regulation, the National Association of Insurance Commissioners (the NAIC) started a drafting process for RBC in 1990, although some states already had their own ideas about RBC before then. In August 1991 the NAIC released the first draft of their proposals. After input from the U.S. industry, a second draft was released in June 1993, and in December 1993 RBC was formally adopted by the NAIC. 
1.2.3 In 1995 U.S. property/casualty insurers have published their first financial reports that will be used as the basis of the required $R B C$ calculations.

1.2.4 The European Union's First Non-Life Insurance Directive commits the E.U.'s member states to reviewing the present solvency margin formula, and it is well known that the Department of Trade and Industry (DTI) is conducting research into possible alternative approaches. The authors understand that the concept of RBC is favoured by at least some within the DTI. In addition, the Association of British Insurers (ABI) has established a Steering Group to recommend a policy for the $A B I$ on this solvency margin review.

1.2.5 Actuaries have a role to play in these forums, and the authors, therefore, believe it important that the actuarial profession debates the issues. Some of the authors would have liked to have proposed, in detail, a specific RBC formula for debate. We have not, however, gone that far, but instead, we have tried to point to areas for consideration by those who might be setting up such a formula.

\subsection{Layout of Paper}

1.3.1 The section headings in the remainder of the paper are as follows:

- the requirement for capital;

- RBC formulae;

- U.K. RBC;

- capital allocation;

— insurance supervision; and

- conclusions.

1.3.2 In Section 2 we discuss non-life insurers' requirement for capital to support solvency, describing how this need for capital depends on the risks in the business, how (if at all) these risks and the capital required can be measured, and how the various risks inter-relate. We discuss insurer solvency and the problems of how to measure and compare the financial strength of insurance companies.

1.3.3 We consider various types of risk that an insurance business is subject to, how these various risks interact, and how an insurer can mitigate the effect of these risks in combination. We also consider miscellaneous factors that, while potentially significant, are difficult to measure or to incorporate into a mathematical formula.

1.3.4 In Section 3 we describe the U.S. RBC formula, and describe the proposals for risk weightings at Lloyd's. Some comments and criticisms of the U.S. formula are included.

1.3.5 In Section 4 we describe a possible U.K. approach to RBC for regulatory purposes, outlining how a $\mathrm{RBC}$ formula could be constructed for the U.K.

1.3.6 In Section 5 we consider the application of RBC considerations to operational management and issues of capital allocation, including reasons for allocating total capital to business units, how such an allocation could be carried 
out using RBC ideas, how relative performance can be measured by reference to capital allocations and return on capital pricing techniques.

1.3.7 In Section 6 we look at the considerations that an insurance regulator is faced with, including objectives, possible actions, desirable features of a solvency test, the stringency of solvency tests, and how public the results of such testing should be. We also look at other approaches to complement a RBC formula, such as 'dynamic solvency testing' (DST) and statutory professional involvement.

1.3.8 In Section 7 we present some conclusions.

\section{THE REQUIREMENT FOR CAPITAL}

2.1 In this section we consider, from the regulator's viewpoint, how the need for capital (including in this definition not only legal capital, but also retained reserves plus or minus any hidden valuation margins) depends on the risks in the business, how these risks and the capital required can be measured, and how the various risks inter-relate. We also consider, to some extent, what can be done where measurement of risks is difficult.

\subsection{The Need for Capital}

2.2.1 There are many reasons why a non-life insurer needs capital. Claimspaying ability is of paramount importance, particularly for the regulator, and even more so for the policyholder. Other reasons for capital could include the desire to maintain dividend payments during periods of unprofitability, the desire to have the potential to invest in other projects, such as organic or acquisitive growth, and the need to support other risks, such as life business. The validity of these reasons may be open to question, but, from the regulator's viewpoint at least, the actual reasons for the capital are largely irrelevant - what matters is the effect on the insolvency risk (i.e. the claims-paying ability). For a non-life insurer, claimspaying ability is largely dependent on the overall amount of available assets in relation to the overall amount of liabilities. It does not solely depend on the adequacy of the technical provisions, nor solely on the insurer's surplus, or capital and reserves (which we refer to simply as 'capital' in this paper).

2.2.2 Prudential margins in the technical provisions may exist by virtue of, among others:

- equalisation reserves;

- provisions for adverse deviations;

- undiscounted reserves; and

- conservative asset valuation.

2.2.3 Provided the provisions are adequate in other respects, these margins increase the expected value of the solvency margin beyond the published solvency margin (including both the statutory minimum margin and the remaining net assets or shareholders' funds). To the extent possible, capital requirements should, therefore, reflect any existing margins, positive or negative, in the 
measurement of assets or liabilities. However, since the solvency margin is the difference between two monetary amounts (assets and liabilities), each of which is susceptible to variation, there can rarely, if ever, be an absolute guarantee of solvency. Capital adequacy is, therefore, at best a probabilistic notion, and is relative to the varying degrees of confidence that may be considered desirable.

2.2.4 Although liquidity is not often considered a problem for an insurer that is stable or growing, simply considering book assets minus book liabilities is not enough, even after adjusting for the margins itemised in 12.2 .2 . The overall capital requirements should include allowance for working capital (to provide the ability to fund cash flows), and the contingency of going into run-off should not be ignored (see $\Uparrow 2.4 .30$ ).

2.2.5 A business not only needs to know that its total reserves are adequate, it also needs to be assured that its reserves are available when they are required. The relationship between the timing of the asset receipts and the likely timing of the liability outgo is, therefore, very important. Thus, there is a need to look at a company on a dynamic rather than a static basis.

2.2.6 Insurer insolvency is the concern, not only of existing or potential future policyholders or of regulators on behalf of policyholders, but also of shareholders, despite the apparent conflict between security for policyholders and return on capital for shareholders. First, shareholders cannot realise their desired return on their investment in an insurance company unless the company continues to meet its obligations to policyholders. Second, even if caused by just a few companies, any failures within the insurance industry, due to under-capitalisation, tarnish the industry's image, since they undermine the trust of the customers and potential customers. Insurance industry analysts recognise these considerations, but tend to look at the industry's overall position. Insurer rating agencies are concerned with means of assessing claims-paying ability, but concentrate on individual companies, largely in comparison with industry norms.

2.2.7 To ensure solvency, it is not sufficient to charge high enough premiums (even if it could be known with certainty that that is happening). To continue to be able to meet claims and claims handling obligations as they fall due, a nonlife insurer has also to retain adequate reserves and invest prudently, while at the same time managing its accumulations of risk by limiting its concentrations of exposure or transferring the risk effectively to alternative solvent risk carriers.

\subsection{Risk Concepts}

2.3.1 'Risk' is difficult to define, but could be described as the possibility that events will develop worse than planned. If everything were known with certainty, then the job of management and the regulator would be easy. However, management do not know what premiums to charge, nor how much to reserve, nor what investment return will be made. Both the variability and the uncertainty are important in understanding risk.

2.3.2 All business is subject to risk in the above sense, yet, for most industries, it has not been deemed necessary for regulatory bodies to insist on a 
minimum solvency margin. A major reason why this is required of insurance businesses is that insurers are regarded as trustees for what is, in effect, policyholders' money, whereas in many other businesses the goods or services are delivered either in advance of, or very soon after, the consideration is paid. In other words, 'trust me' is a major element of what the insurer is selling. Policyholders' stakes have been compared to debtholders' (see Bride \& Lomax, 1994), but without the covenants that are common with loans to ensure management discipline.

2.3.3 Many business processes can be described by a probabilistic model. In insurance the claims process is often modelled by a random number of claims and a random amount of each claim. This model could, in principle, include the effects of policy limits and excesses, claims handling expenses and the timing of payments.

2.3.4 The process risk is the variability due to the random nature of the outcomes. However, given this random structure, the underlying model (if one exists at all) is unknown. The only information that can be gained about it is by observing the random results that it has thrown up in the past. The parameters which describe this structure can be measured, subject to a confidence (or uncertainty) level. The likelihood that these estimates will not be exactly equal to the 'true' parameters gives rise to the parameter uncertainty. In addition, there is the potential that the selected model structure is not the right one. Alternative model structures can be proposed, which will yield alternative results for the aggregate loss amount distribution. This yields the specification error. The authors have deliberately used three different terms ('risk', 'uncertainty' and 'error') in order to draw attention to the differences between these concepts.

2.3.5 These three fundamental concepts (process risk, parameter uncertainty, and specification error) apply in many situations. Typically, the process risk is the least significant, but most easily modelled and incorporated into a formula. The parameter uncertainty is measurable, but it is sometimes forgotten. It can, however, be of greater significance than the process risk. The specification error is the least tractable of the three, but probably the most important.

2.3.6 A great number of business processes cannot, however, readily be modelled probabilistically. These may give rise to risks that are of even greater significance than those that can be modelled and included in a RBC formula. At this point, some may question the value in even trying to construct a RBC formula. However, we believe that this simply means that a different, complementary approach is needed by regulators to address these issues.

2.3.7 Another distinction that can be drawn is that between long-term, creeping risks and short-term risks. The manifestation of long-term risks will have a different incidence from the exposure to them. For instance, any delay in recognising a trend will give rise to a discontinuity in the provisions when it is finally recognised. 


\subsection{Insurance Risks}

2.4.1 Given that insurance regulators require a minimum solvency margin, what are the risks to which an insurance business is subject and which should, therefore, be taken into account by such a minimum solvency margin? Other authors have identified lists of these risks, for example Pentikäinen (1982) and the Institute of Actuaries Guidance Note GN12 (ПT4.1 and 4.2). We have attempted to compile as complete a list as possible, but, inevitably, we will not have identified every risk possible.

2.4.2 The most obvious risk factor is uncertainty of claim costs. Additional risks are volatility in the economic value of assets, the creditworthiness of debtors and future expense levels.

2.4.3 The uncertainty in claim costs applies both to reserves for claims on business already written and to the profits or losses expected from business yet to be written. To some extent, under-reserving for past business is likely to be associated with underestimation of required premium levels on future business. While both of these may be mitigated, to some degree, by appropriate professional advice, the risks referred to above still remain.

2.4.4 Uncertainty of claim costs is dependent on the lines of business written by the company. Different lines of business have different risk characteristics and may be, to some extent, independent, or at least only partially correlated. Significant differences are found between direct and reinsurance business. The DTI accounting classes and E.U. authorisation classes are too broad to measure all the significant differences between types of business. DTI risk groups are more detailed, but are not standardised, and depend on a company's own classification system.

2.4.5 Trends and cycles contribute to the overall risk. The perils which give rise to insurance claims and the forces behind them are not static, but change over time. The causes of change may be legal, technological, social, economic, fiscal, political or environmental. The effect of these changes may be retrospective as well as prospective. Changes can be exhibited as trends or cycles, and it is often not easy to distinguish between the two.

2.4.6 The importance of trends and cycles, as regards insurance capital adequacy, is that an insurance business should be able to survive a period of under-pricing (either deliberate or accidental) due to competitive pressures, and also should be able to withstand under-estimation of costs due to misreading secular changes or failing to anticipate extraordinary changes.

2.4.7 Inflation and currency mismatch increase the overall risk. Inflation, the persistent tendency of the prices of goods and services to rise over time, is a long-term risk in the sense that actual inflation may differ from expectations. The sometimes unavoidable mismatching of premiums and claims by monetary currency is a short-term or acute risk. Currency movements can be very dramatic, and can take place in a period of minutes.

2.4.8 The investment of assets, even in the form of cash, is subject to risk, because there is no investment that can be used precisely to match assets with 
insurance liabilities. Total asset risk can be thought of as comprising income risk capital value risk and mismatching risk. Interest rate risk may persist for an extended period of time, affecting cash flows. Asset value risk includes both permanent diminution in the value of an asset and temporary changes in its market value. Temporary changes matter if investments need to be realised at a time other than that which was planned or if there is deliberate mismatching of assets and liabilities. Mismatching risk arises, essentially, because of differences between the asset and liability portfolios in their nature, terms and currency.

2.4.9 The mix of the investment portfolio will be important in minimising concentration of risk in absolute financial terms. This may mean limiting the total investments in a particular company or type of asset. Also, the correlation in performance of various types of assets held is important.

2.4.10 Insurance risk is also dependent on the exposure to catastrophic losses. While this can be thought of as an application of risk theory to nonindependent risks, the accumulation of risk highlights certain issues.

2.4.11 Certain insurable interests, such as North Sea platforms, are large enough in themselves to present the potential for a catastrophic loss.

2.4.12 Certain perils, either natural or economic, can give rise to a number of claims arising from a single 'event'. The catastrophic potential of windstorms, earthquakes, and floods, for example, are well known. Similarly, economic events have catastrophic potential; for example, a decline in economic conditions can give rise to a large number of claims from different coverages, such as mortgage indemnity guarantee claims, redundancy insurance claims, and theft claims, as well as fraudulent claims of various types.

2.4.13 Judicial, legislative and regulatory decisions can also have a catastrophic impact. For example, the U.S. 'Superfund' (pollution) legislation created a huge, unanticipated liability, resulting in a large number of claims. The introduction of strict liability for pollution in Europe may have a similar impact. It is difficult to see how such risks can be quantified in advance.

2.4.14 The link between all these is the happening of a single 'event' and an aggregation (or clash) of coverages. The factors which affect how an insurance business will be impacted by such a single event include its limits of coverage aggregated over discrete, independent policy groupings, and its reinsurance protection (subject to the security of its reinsurers).

2.4.15 All businesses operate in the same economic, fiscal and legislative arena, and there are many credit risks which are non-insurance related (e.g. fraud and poor management) which may apply to all types of normal company assets. The data for measuring this risk are, therefore, wider than just that for the insurance industry.

2.4.16 However, the insurance business gives rise to certain specialised classes of debtors:

- Brokers' and agents' balances. The nature of these organisations and how they themselves are regulated have an impact on the default risk. 
- Reinsurers. There are two main areas where reinsurers' credit risk needs to be assessed, namely:

(a) In the long term, how likely is the reinsurer to be able and willing to meet the future cost of such claims?

(b) How promptly will the reinsurer pay those recoveries currently outstanding?

2.4.17 Correlations between the market conditions and experience of insurers and those of their reinsurers is important. First, reinsurers are likely to be least able to pay claims at the bottom of the underwriting cycle. Second, the larger gross claims and aggregations of claims will impact both insurers and reinsurers simultaneously.

2.4.18 In addition to various balance sheet items and their susceptibility to individual perils, there is also the interrelationship between items and between perils, leading to the notion of covariance, i.e. the degree to which factors move together rather than independently.

2.4.19 The concept of covariance applies to the interrelationship between lines of business, between past and future business and between asset and liability values (provided these are well matched).

2.4.20 In the following paragraphs we describe those factors that are likely to be relevant to capital adequacy, but that are difficult to measure or incorporate in a formula.

2.4.21 With increased size there can be economies of scale, but, while a large company may have diversified into a large number of different lines of business, it is not necessarily less risky than a company specialising in a single line. It may be more difficult to manage a diverse portfolio than a single line that the company understands well, and the difficulty of managing disparate activities may increase the correlations between risks.

2.4.22 Rapid growth needs to be considered in the context of inflation and by line of business, trying to identify the causes of abnormally high growth. There are often problems of infrastructure or expertise in starting out in a new direction or expanding rapidly in a given area. Abnormally low growth or reductions in size could also be a signal of problems to come.

2.4.23 In their paper to the Casualty Actuarial Society, Redman \& Scudellari (1992) examined a number of reports concerning the causes of insolvency in the U.S.A. Rate of growth proved a significant factor associated with insolvencies. Size, measured by 'policyholder surplus', was not found to be an important factor. Without understanding, for example, the relationship between policyholder surplus and business volumes in the samples, it is difficult to explain these results. However, they may be simply a manifestation of the relative importance of process risk, parameter uncertainty and specification error.

2.4.24 There is a variety of different ownership and corporate structures that can exist. Relevant factors to consider relating to the structure are:

- How is the holding company financed? 
- How is any borrowing financed?

- Are there guarantees between companies in the group or with third parties (such as a guarantee from a former owner of the business or a guarantee to the new owner of a divested part of the business)?

- How would a third party find out about such an onerous guarantee?

- A parent company may give a guarantee to the insurance company, but how much weight should be given to it?

- A guarantee may be insufficient in a run-off situation.

- Are there other financial arrangements that affect the insurance company?

- What is the quality of management in related companies?

- How will any problems in related companies affect the running of the insurance company?

- How is the parent regulated?

- What reliance can be placed on the accounts of the parent and related companies, particularly if they have been prepared under different accounting conventions?

2.4.25 Management competence is a 'soft' issue that RBC formulae would not readily be able to deal with. What soft data could be used? The history of individual managers may be relevant, but it is difficult to see how to score this on a numerical scale. The E.U.'s Third Non-Life Insurance Directive has a requirement for 'sound and prudent management'. While this is largely undefined in the Directive, some criteria have been defined in the U.K. by Schedule 1 to the 1994 regulations implementing the Directive. According to earlier U.K. legislation, a manager should be 'fit and proper', but this is not the same thing as sound and prudent management. The ABI is producing guidance notes on several aspects of operational management. Compliance with these may be a guide to management competence.

2.4.26 Adaptability and short reaction time to adverse trends can mitigate insurance risk, but it may not be easy to measure. Also, adaptability can only be assessed in hindsight, and it may well be the unforeseen that causes problems.

2.4.27 The management may be centralised or decentralised, with implications for control and speed of reaction. The control of underwriting may be in-house or exercised through agencies. In the latter case, the management structure and quality of the agencies needs to be considered.

2.4.28 The adequacy of human resources is important, for instance the number and quality of claims adjusters dealing with claims and underwriters dealing with incoming risks. The adequacy and quality of management information, information technology resources and investment skills are also relevant.

2.4.29 The degree of independence and supervisory control exercised by the main board is likely to be particularly pertinent.

2.4.30 Usually an insurance business will be run as a going concern. Going into run off (i.e. ceasing to accept either new or renewal business) is an extreme 
case of fluctuation in business volumes. The potential that an insurance company may, at some time, discontinue active underwriting will emphasise certain risks and expose new ones. For example:

- The technical reserves may prove to be inadequate. This is equally possible for a company continuing to write business, but it may not be apparent to the outside world until after the company has recovered.

- The company may find itself subject to selective cancellation of policies, possibly mitigated by onerous short-term rates that it can impose on policyholders.

- Non-renewal of certain types of policy may trigger onerous extended coverage or reporting provisions for little or no additional premium.

- Overhead expenses may rise relative to the amount of claims being handled, both in the immediate term, before appropriate staffing levels (and office space) have been established, and in the longer term, because of diseconomies of scale.

- Direct claims costs may rise owing to a reduction in control, as the more competent and ambitious staff leave for more rewarding jobs and goodwill is lost, and this effect is likely to persist.

- Outward reinsurance costs may rise owing to the mismatch between the accident period basis of cover and the underwriting period nature of risks written.

- The expected reinsurance recoveries may be reduced as the reinsurers delay payment or exercise any rights of offset, control is lost over identification of potential recoveries and brokers become slower in recovering funds.

- Cash flows are likely to become negative, forcing the realisation of assets.

- The realisable (economic) values of some assets may prove to be lower than the accounting values.

2.4.31 There may be benefits of going into run-off, such as the possibility of being able to agree commutations on favourable terms (though this is not a benefit to the policyholders whose policies are commuted) and the inability of the company to write further loss-making business. However, all things considered, there are probably additional costs involved in going into run-off, which may not already be provided for in any technical provision.

2.4.32 Since the option to cease trading is one that can potentially be exercised against existing policyholders, the regulators would be equally concerned with valuing the assets and liabilities on a run-off basis as with using a going concern basis.

\subsection{Mitigation of Risk}

2.5.1 Possible actions which may be taken by management to mitigate the inherent risk of an insurance enterprise are:

- avoiding an undue concentration of risk: in business written, in invested assets, in reinsurance ceded; 
- diversifying by obtaining exposure to areas with different risk characteristics (this principle is applicable to business written, invested assets and reinsurance, and includes diversification by: country/economy, currency, industry, class of business written, types of assets (e.g. bonds equities), types of reinsurance (e.g. proportional, non-proportional) and size of company); and - reducing the impact of risk by appropriate reinsurance; matching assets and liabilities by currency, term, broad category of asset and cash flows; hedging investment portfolio using options, futures, other derivative instruments.

\section{RISK-BASED CAPITAL FORMULAE}

3.1 In this section we critique the U.S. RBC formula. We also give some general comments on the proposals for risk weightings at Lloyd's, although these should not be taken as a considered response to the Lloyd's consultative document that was issued in August 1995, after the initial draft of the present paper (see Lloyd's of London, 1995). The process of critiquing an existing system highlights some potential pitfalls in constructing an RBC formula for use in the U.K.

\subsection{The U.S. RBC System}

3.2.1 The U.S. insurance market is introducing, state-by-state, a common RBC regulatory system. The following paragraphs give a brief description and critique of the U.S. RBC formula for property and casualty insurers. More details can be found in reference National Association of Insurance Commissioners (1993).

3.2.3 The U.S. RBC formula determines an amount for each insurer, known as the Authorised Control Level. Depending on the level of the company's free capital relative to its Authorised Control Level, the company and/or the regulatory authorities may or must then take various actions.

3.2.4 The different action levels are indicated in Table 3.1.

Table 3.1. U.S. regulatory action levels

below $70 \%$ The company must be seized by regulators. This is called the Mandatory Control Level. $70-100 \%$ The company may be seized by regulators. This is the Authorised Control Level.

$100-200 \%$ The company must submit a plan of action to regulators. The Regulatory Action Level is set at $150 \%$, below which the regulators will perform an examination of the company and issue a corrective order. Above $150 \%$, but below $200 \%$, is known as the Company Action Level, where the company's actions alone are deemed to be sufficient, without the need for a regulator's corrective order.

$250 \%+\quad$ Typical value for the vast majority of companies.

3.2.5 For 1994, the authorised control level RBC is equal to $40 \%$ of the total $\mathrm{RBC}$ after covariance adjustment. It has been announced that this $40 \%$ factor will be increased to $45 \%$ in 1995 and $50 \%$ in 1996. 


\subsection{How is the U.S. RBC Formula calculated?}

3.3.1 The RBC formula is made up of several components. Essentially, it comprises:

- asset risk;

- credit risk;

- underwriting loss and loss adjustment expense (LAE) reserve risk;

- underwriting premium risk; and

— off balance sheet risk.

3.3.2 Asset risk requires a consideration of the classes of assets in which the insurance company invests, the diversification of the insurance company's portfolio of assets, and the insurance company's exposure to individual companies in which the assets are invested. The risk being measured is that the assets are not realisable at their anticipated values.

3.3.3 Credit risk includes the risk of default by entities that hold funds to which the insurer has, or may have, a claim, which include brokers and agents as well as reinsurers.

3.3.4 Underwriting reserve risk refers to the possibility that the insurance technical reserves may be less than the final cost of settling the claims that they represent. There is usually much uncertainty in the ultimate losses that are implied by the reserves, because of the imperfect nature of the information and because the ultimate settlement cost of the claims and expenses that the reserves represent will be affected by future events that may not follow established trends or assumptions made by the company. The risk includes that for incurred but not reported claims, as well as for reported but not settled claims. Each line of business is considered separately, with some allowance for diversification.

3.3.5 Underwriting premium risk refers to the possibility that premiums being received now, and in the near future, may prove insufficient to pay for the claims and expenses that will arise from the contracts written. The well-known insurance pricing cycle means that this factor will be of greater significance at some points of time than at others. For an individual company, the factors affecting the pricing cycle also include risk selection and other mitigating factors. Each line of business is considered separately, with some allowance for diversification.

3.3.6 The RBC formula views the underwriting and reserving risk on a tenyear time horizon, taking this as a reasonable time span over which to measure the potential for adverse deviation. The loading for these risks is computed by multiplying together either the net premium or net reserves (as the case may be) for each line of business and various loading factors. These factors reflect the industry experience in these lines, subject to company-specific adjustments.

3.3.7 It is necessary to consider what values are being measured, and whether the accounting values properly reflect economic values. The components of risk need to be viewed in economic, rather than accounting, terms, so, to the extent that assets are not valued at market values and liabilities are not valued with regard to future investment income and capital gains, there may be hidden 
margins in the accounting numbers. The RBC formula takes some account of these features, in making adjustments to the figures in the financial statements.

3.3.8 Investments in subsidiaries and related companies are a special case, where it could be relatively easy for a company to 'manage' its required capital by altering its legal structure.

3.3.9 An additional factor, that is thought to lead to greater risk in an insurance company, is high growth, and this is given a special loading referred to as the 'off balance sheet risk charge'.

3.3.10 Risk charges (i.e. the required margins for adverse deviation) are calculated for the components listed in \$3.3.1. These are summarised diagramatically in Figure 3.1. These charges are then summed to give the total RBC (before covariance adjustment). However, this total is regarded as giving too high a required margin, since adverse deviations in the various components are likely not to occur simultaneously.

3.3.11 The total RBC charge after covariance is equal to the result of the following formula:

$$
R_{0}+\sqrt{ }\left(R_{1}^{2}+R_{2}^{2}+R_{3}^{2}+R_{4}^{2}+R_{5}^{2}\right)
$$

where $R_{0}$ to $R_{5}$ are $\mathrm{RBC}$ charges, described in Figure 3.1. The covariance adjustment is then simply the difference between the straight sum of $R_{0}$ to $R_{5}$ and the result of the formula above.

3.3.12 The reason for incorporating a covariance adjustment in the RBC formula is that the total $\mathrm{RBC}$ for an insurer should generally be less than the simple sum of the RBC amounts for each risk element, because of the benefits of diversification and because the separate risk elements are not perfectly correlated.

3.3.13 It is worth pointing out here that, if the risk charges were intended to be directly proportional to the standard deviation of the corresponding random variable, then the above so-called 'square root rule' would be precise if and only if the correlation coefficient between the random variables were zero. However, the risk charges are not intended to be directly proportional to the standard deviations, and the square root rule is simply a practical device for reducing the overall risk charge. Based on the conceptual framework of 'expected policyholder deficit' (see 14.2.5), the Actuarial Advisory Committee to the NAIC Property/Casualty Risk-Based Capital Working Group (1993) found the square root rule to be appropriate where there is a weak positive correlation between the different risk factors.

3.3.14 The covariance adjustment is the difference between the simple sum of $R_{0}$ to $R_{5}$ and the above formula. The adjustment is a very substantial element of the RBC calculation, and, according to NAIC estimates, it would represent around $40 \%$ of the RBC before covariance for a typical insurer.

3.3.15 The items in the RBC formula also make allowance for asset concentration, premium and reserve concentration in a particular line of business and excessive growth. 


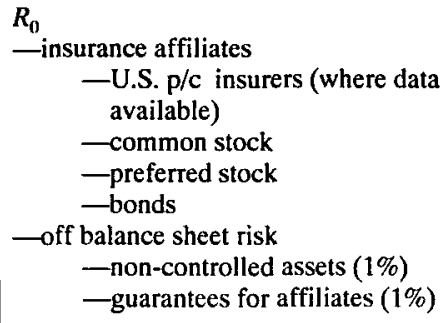

\section{Covariance}

$$
R_{1}
$$

-fixed income risk

-bonds, excluding $R_{0}$ (various $\%$ )

-bond size adjustment

-mortgages $(5 \%)$

-collateral loans $(5 \%)$

-cash $(0.3 \%)$

-short-term investments $(0.3 \%)$

-asset concentration adjustment

(for fixed income items)
$R_{2}$

-equity risk (common \& preferred stock)

-non-affiliated stock (various \%)

-affiliated life insurers (50\%)

-affiliated alien insurers (50\%)

-all other affiliates $(22.5 \%)$

-real estate $(10 \%)$

-other invested assets $(20 \%)$

-aggregate write-ins (5\%)

-asset concentration adjustment

(for equity items)

$$
R_{3}
$$

$-50 \%$ of credit risk

$-r / i$ recoverables penalty $(10 \%)$

-interest, dividends and real estate (5\%)

-income due and accrued (1\%)

\section{$R_{4}$}

-underwriting reserve risk

-adjusted for claims made

-adjusted for loss-sensitive contracts

-adjusted for concentration

-off balance sheet risk

-reserve growth risk

$-50 \%$ of credit risk (see $R_{3}$ )

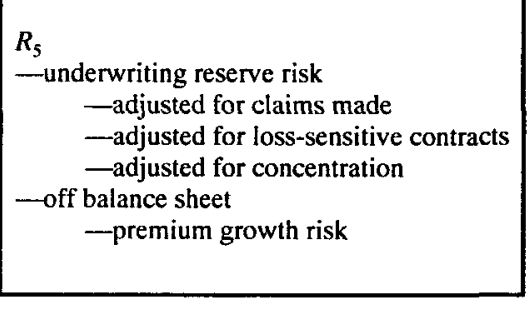

Figure 3.1 Components of NAIC's Risk-Based Capital formula 


\subsection{Comments on the U.S. RBC System}

3.4.1 Any $\mathrm{RBC}$ system that is to be used by regulators to monitor the solvency of insurers needs to reflect a balance between political, theoretical and practical considerations. Such a system needs to be reasonably straightforward to operate in practice. The U.S. formula is, therefore, of necessity a broad brush approach to setting capital requirements, and so some very specific features of companies are likely to be ignored.

3.4.2 However, there are a number of criticisms that can be made of the U.S. system, which should be borne in mind when considering the possible structure of a U.K. formula. The principal criticisms of the U.S. formula are set out in the following paragraphs.

3.4.3 The actions described in Table 3.1 may be regarded as being quite rigid, in that they give a relatively small amount of discretion to the regulator. Also, it could be argued that the policyholders are disadvantaged if they are required to pay additional premiums to service additional capital. However, this can be disputed, since the additional capital reduces shareholders' risk and can, itself, be invested to earn a fair rate of return in the capital markets, subject to regulatory investment restrictions. Various viewpoints on this are expressed in D'Arcy \& Doherty (1988), Ryan \& Larner (1990) and Bride \& Lomax (1994).

3.4.4 Several types of risk appear not to have been incorporated into the U.S. formula, including:

- there could be a substantial adverse movement in the market value of the company's investments, as opposed to normal investment volatility;

- the nature, currency and term of the company's assets could be inappropriate, given the nature, currency and term of the liabilities;

- the company could be exposed to an accumulation of risk, either from a natural disaster or from a combination of economic conditions; and

- there could be a significant loss due to exposure to investment trading, e.g. in derivative instruments, for speculation rather than hedging.

3.4.5 The calculation of a number of the risk factors appears to be arbitrary. For example:

- the charge against reinsurance ceded in the credit risk factor; and

- the allowance for excessive growth in the off balance sheet risk factor.

3.4.6 There is not a consistent conceptual framework for the calculation of risk charges. The loss and LAE reserve risk factor and underwriting premium risk factor are based on worst case industry experience during the last ten years, whereas the stock risk factor is, we understand, based on a statistical measure of variability (see American Academy of Actuaries Property/Casualty Risk-Based Capital Task Force, 1993).

3.4.7 The authorised control level $\mathrm{RBC}$ is equal to $40 \%$ of the total $\mathrm{RBC}$ charge after covariance (though this factor will be increased to $45 \%$ in 1995 and $50 \%$ in 1996). It is unclear what this $40 \%$ factor represents, but it probably 
reflects political considerations to some extent, rather than being justified on the basis of a coherent conceptual framework.

3.4.8 The method of calculation of the covariance factor adjustment, using the square root rule, is simplistic (see 13.3.13), particularly when one considers the financial significance of this term (see Table 3.2). The formula does not distinguish different levels of correlation between risk factors which may apply to different companies.

3.4.9 The loss and LAE reserve risk factor and underwriting premium factor are based on rolling ten-year worst-case industry experience. In particular, this means that the factors for the 1994 year-end reflect the historical experience of the U.S. industry in the period 1984-93, including the severe adverse development that occurred in general liability, medical malpractice and reinsurance, and the very severe loss ratios in medical malpractice and reinsurance.

3.4.10 The experience during this particular period was dominated by several factors:

- the U.S. tort liability explosion, particularly in relation to medical malpractice;

- the emergence of asbestos and environmental pollution claims;

- an apparent increase in the frequency of natural catastrophes;

- high interest rates, creating pressures to engage in cash flow underwriting; and

- high inflation rates.

3.4.11 While the next underwriting down-cycle could easily be as severe as the last, the specific forces that drive it will probably be different. For example, there may be a different incidence of natural catastrophes. The distribution of adverse results by line will probably also be different.

3.4.12 The factors are based on retrospective, rather than on prospective, considerations, and are tuned to the features of the chosen period. If the structure of a sector of the market has changed fundamentally, there is no logical reason why the experience of the past ten years should be representative of future experience.

3.4.13 The effectiveness of the company-specific adjustments to the reserve risk factor is questionable. If a company has taken corrective action and increased its reserves from an inadequate level to an adequate level (or vice versa) during the past ten years, the RBC formula assumes that such reserve strengthening (or weakening) will continue to take place in the future.

3.4.14 The adjustment for investment income in the reserve factor does not distinguish effectively between discounted and undiscounted reserves. However, this is difficult to achieve, since nominally undiscounted reserves may well be understated compared with reserves that are subject to an explicit discount for the time value of money.

3.4.15 The factors use a fixed interest rate of $5 \%$. This may not be appropriate, because interest rates have fluctuated substantially during the last ten 
years, and the worst case reserve strengthening or loss ratio may correspond to a period when interest rates were significantly different from $5 \%$.

3.4.16 Management risk is an important concept that is missing altogether from the RBC formula, perhaps because of the controversial nature of any scoring system for assessing this. However, in view of our comments, in $\mathbb{2} 2.3 .5$, on the relative sizes of the process risk, parameter uncertainty and specification error, this systematic management risk could well be more significant than any other factor.

3.4.17 Lines of business are classified in the same way as the NAIC annual statement, which eases the calculation. However, this does not necessarily pick up all the appropriate distinctions between classes of business in terms of risk.

3.4.18 Outwards reinsurance is treated very simplistically. There is no distinction between reinsurers with different security standings or offering different collateral security, by way of letters of credit, trust funds, parental guarantees, etc. Also, there is no distinction by the class of business being reinsured, such as between long-tail and short-tail business, or the timing of expected recoveries, or between different types of reinsurance structure, such as between quota share and excess of loss.

3.4.19 The formula discourages management from setting conservative reserves. Because the underwriting reserve risk is calculated as a factor multiplied by the company's reserves, a more strongly reserved company will have a higher required $\mathrm{RBC}$.

3.4.20 The formula penalises high premium rates. The component of $\mathrm{RBC}$ relating to underwriting premium risk is calculated as a multiple of the premiums. Therefore, a company that has high premium rates relative to its exposure will, nevertheless, have the same factor multiplying its premiums as a company with lower premium rates per unit of exposure. There will also be important differences in premium adequacy at different points of the pricing cycle, which will not be picked up in the RBC formula.

3.4.21 The parameters for the formula change dynamically, on a rolling tenyear basis. While this does not fix the parameters statically for all time, there could be significant changes when certain catastrophe years drop into, or out of, the formula.

3.4.22 RBC does not consider the effect of mismatching of the assets and the liabilities. This is an additional risk that an insurance company could be running, which could significantly alter the economic value of the company's capital on a change in the economic climate. In addition, the ease with which investments may be changed from the year-end position has not been reflected in the assessment of the RBC charge for assets, and this seems to be a potentially significant loophole.

3.4.23 The RBC formula does not measure exposure other than by reference to premiums and reserves, but these are the company's own figures, and may, or may not, be a good reflection of the true exposure. In addition, there is no attempt at all in the RBC formula to measure the company's exposure to 
aggregations of risk, or how suitable and secure its reinsurance arrangements are to control this risk.

3.4.24 The credit risk charges do not recognise that the exposure depends, not only on the year-end balances, but also on the annual throughput. They make no allowance for the number, size or age of the individual debtors.

3.4.25 There are significant changes for some classes of business in the capital requirements compared with previous industry norms. Even though these changes may be desirable in other ways, they are likely to have a disruptive influence on the market for these classes of business, which may not be what is intended.

3.4.26 The formal RBC calculation is essentially a regulator's tool. The RBC formula focuses on the need for capital to satisfy criteria that set a sufficiently high level of probability of a company's continued solvency over a relatively short time-frame. Although relating capital to risks is not itself purely a regulatory issue, but one of business discipline, the RBC formula does not, of itself, provide a measure that can be used to judge the performance of companies in terms of their risk/reward profile to investors. Some thoughts on how RBC could be used for performance measurement are given in Section 5 .

\subsection{NAIC's Analysis of 1991 RBC}

3.5.1 The NAIC's analysis of 1991 data (see National Association of Insurance Commissioners, 1993) suggested that the total RBC for the U.S. property-casualty industry would be made up of $23 \%$ asset risk, $10 \%$ credit risk, $44 \%$ reserve risk, $23 \%$ underwriting risk and less than $1 \%$ off balance sheet risk. The controversial covariance adjustment is highly significant, reducing the overall RBC by more than $40 \%$. Table 3.2 illustrates this.

Table 3.2 NAIC analysis of $1991 \mathrm{RBC}$ by category

$\begin{array}{lcc} & \$ \div 10^{9} & \% \text { total RBC } \\ \text { Total industry surplus } & 170.2 & \\ \text { Asset risk } & 28.5 & 22.6 \\ \text { Credit risk } & 12.4 & 9.8 \\ \text { Off-balance sheet risk } & 1.2 & 0.9 \\ \text { Underwriting loss and LAE reserve risk } & 55.0 & 43.5 \\ \text { Underwriting premium risk } & 29.3 & 23.2 \\ \text { RBC before covariance } & 126.4 & 100.0 \\ \text { Covariance adjustment } & (51.8) & (41.0) \\ \text { RBC after covariance } & 74.6 & 59.0 \\ \text { Authorised control level } & & \\ \text { (40\% of RBC after covariance) } & 29.8 & \end{array}$

Source: National Association of Insurance Commissioners Exposure Draft-June 1993

3.5.2 The same NAIC analysis indicated that only $4.3 \%$ of U.S. property- 
casualty insurers would have fallen within one of the action levels. The breakdown of insurers by action level is indicated in Table 3.3.

Table 3.3 NAIC analysis of 1991 surplus by action level

$\begin{array}{lccc}\text { Total surplus, as \% authorised control } & \text { Number } & \begin{array}{c}\text { Percentage, } \\ \text { level RBC }\end{array} & \begin{array}{c}\text { Cumulative } \\ \text { percentage, \% }\end{array} \\ 0-70 \% \text { (Mandatory control level) } & 27 & 1.5 & 1.5 \\ 70-100 \% \text { (Authorised control level) } & 8 & 0.4 & 1.9 \\ 100-150 \% \text { (Regulatory action level) } & 22 & 1.2 & 3.1 \\ 150-200 \% \text { (Company action level) } & 21 & 1.2 & 4.3 \\ 200-250 \% & 38 & 2.1 & 6.4 \\ 250 \%+ & 1,691 & 93.6 & 100.0 \\ \text { Totals } & 1,807 & 100.0 & 100.0 \\ \text { Number < } 100 \% & 35 & & \\ \text { Number <200\% } & 78 & & \end{array}$

Source: National Association of Insurance Commissioners: Exposure Draft-June 1993

\subsection{Risk Weightings at Lloyd's}

3.6.1 Lloyd's is regulated differently from U.K. insurance companies. The Policyholders' Protection Act does not apply to business written at Lloyd's, and the solvency requirements need to reflect Lloyd's matrix structure, with security being provided by Names (representing one dimension of the matrix), who have varying participations across the various syndicates (representing the second dimension).

3.6.2 There are, at present, no explicit DTI capital requirements at Name or syndicate level. The DTI is interested in global, not Name-level, capital adequacy, and Lloyd's global returns must satisfy the DTI in terms of having both technical reserves and an appropriate solvency margin. However, the global figures do not net off inter-syndicate reinsurance, and thus increase the required solvency margin. The statutory minimum solvency margin is covered by earmarked assets, although there is further reliance on other assets which provide an aura of hidden strength.

3.6.3 Based on a syndicate level analysis, Names must satisfy capital adequacy requirements, set by Lloyd's and approved by the DTI. These requirements are expressed in terms of minimum reserves - there is no Name's solvency margin as such. Historically, the minimum amounts had to be the higher of 'Test 1' percentages of premium income (set by Lloyd's and varying by line of business) and 'Test 2' estimates (established by the syndicate's managing agents, and at least as great as the Reinsurance to Close, if any). However, from the 1993 year-end, actuarial certification, on a prudent basis, can be used to justify reductions in reserves if the 'Test 1 ' percentages are unduly conservative (see Institute Guidance Note GN20).

3.6.4 A Name's reserve in respect of Syndicate XYZ is the Name's 
proportion of Syndicate XYZ's minimum reserves. A Name's overall reserve is the sum of that Name's reserves across syndicates. However, to the extent that there are margins in these reserves, there would be scope for applying a 'covariance factor' to reduce the Name's overall reserve below the simple sum of that Name's reserves across syndicates. However, the interaction between syndicates is difficult to assess, making such a covariance adjustment problematical. Until the advent of RBC in Lloyd's, no covariance adjustment was made.

3.6.5 Additionally, underwriting is restricted by reference to a Name's means. As a way of ensuring sufficient assets to cover losses on future underwriting, this is arguably better than a retrospective solvency margin requirement. However, the way this was done in the past did not relate capital to the underlying risks in any meaningful way.

3.6.6 As part of the significant changes that are taking place in the market, Lloyd's has accepted that its old minimum capital rules are no longer appropriate in the new environment. The old rules allowed a Name to put up the same amount of capital regardless of the syndicates that he or she was on, and regardless of the business being written by those syndicates.

3.6.7 Lloyd's has concluded that this old, stamp-based system for allocation of capital is untenable, and believes that the move to RBC is inevitable. In August 1995, Lloyd's issued a consultative document (see Lloyd's of London, 1995 ) on the proposed system of capital requirements. This proposed system will rest on a formula that takes into account the specific features of Lloyd's, including its sources of capital, but based on the same concepts as underlie the U.S. RBC formula for companies. Lloyd's aim, originally, was to introduce RBC for the 1996 underwriting year of account. It was envisaged that this would encompass both individual Names (including those investing via Members' Agents' Pooling Arrangements or 'MAPAs') and corporate Names. It appears, however, to have been decided to apply it strictly only to corporate Names in 1996, with full implementation in 1997.

3.6.8 Lloyd's experience in analysing $\mathrm{RBC}$ requirements has been that a large number of risk categories are required to take into account the complexities of the business that is written in the Lloyd's market. Lloyd's has found little correlation between size or high growth and financial weakness. This should be contrasted with the findings in the U.S.A., referred to in 92.4 .23 , where growth was, but size was not, found to be linked with insolvencies.

3.6.9 Lloyd's intends to measure required capital by reference to a formula that encompasses the following:

- underwriting risk, which includes class of business, spread of classes, spread of managing agents, management capability (i.e. compliance with standards that Lloyd's will set for managing agents, including their structure and systems) and having a credit for outwards reinsurance; and

- reserving risk, which includes, as well as the above factors, the spread of underwriting years. 
3.6.10 With the larger number of risk categories used by Lloyd's, its system will be much more complex than the U.S. formula. However, Lloyd's intends to provide computer software to enable Names or their advisors to see the effect of their existing portfolio and consider the impact of changes. It is also intended to review, and if necessary modify, the Lloyd's model annually, in order to reflect changes in market conditions.

\section{U.K. RISK-BASED CAPITAL}

4.1 In this section we put forward some ideas regarding the possible method of construction of a RBC formula in the U.K. for regulatory purposes. Some readers may be disappointed that we have not attempted to establish a formula that could be debated. We have deliberately avoided this, on the grounds that this would have diverted attention away from the issues set out below.

\subsection{Desirable Features of $R B C$}

4.2.1 First, we consider the desirable features of any RBC formula. These have been considered in the U.S. context by, among others, Cummins, Harrington \& Niehaus (1992).

4.2.2 In our view, a U.K. RBC formula needs to be:

- as comprehensive as possible (albeit necessarily imperfect);

- based on a coherent conceptual framework;

- understandable and easy to calculate;

- robust;

- based on information supplied to the regulator (e.g. via the DTI returns);

- commanding general support;

- unlikely to cause too much undesirable behavioural change (e.g. underreserving in order to achieve a certain published solvency position); and

- reflecting public priorities;

although these features are, to some extent, conflicting.

4.2.3 'Comprehensive' means that the formula should include all reasonably quantifiable risks, and make allowance for steps that can be taken to mitigate them, e.g. by outwards reinsurance, or exacerbate them, e.g. by mismatching of assets and liabilities. It should also allow for differences between companies in the measurement of risk factors, e.g. different standards of reserving, including discounting.

4.2.4 A 'coherent conceptual framework' could include the notions of:

— probability of ruin (see Daykin, Pentikäinen \& Pesonen, 1993);

- 'expected policyholder deficit' (see Butsic, 1992); and

- capital to meet specific circumstances (see $\uparrow \pi 6.3 .5-6.3 .16$ on dynamic solvency testing). 
4.2.5 With probability of ruin, the aim of a risk charge structure could be to limit the probability of ruin to a specified level over a given time horizon. The 'expected policyholder deficit' approach is based on a theoretical pure reinsurance premium to cover the tail of the aggregate loss distribution. The capital to ensure that a certain set of circumstances can be withstood could be by reference to, say, the last ten years of industry experience or scenarios derived from hypothetical large losses. There is no reason, however, why different conceptual frameworks cannot be used in combination.

4.2.6 'Robustness' means that minor changes to circumstances or data should not change the capital requirement significantly, thus making it difficult for companies to manipulate their RBC requirements. The formula should enable the regulator to see through window-dressing, such as well-timed disposals of inadmissible assets. This could be achieved through a requirement for the company to maintain its $\mathrm{RBC}$ at all times and to certify that it has done so. However, this might be difficult to enforce, and may, effectively, increase the RBC requirement. Alternatively, there could be penalties for falling below a proportion of the RBC on an instantaneous basis, or the company could be required to notify the supervisor as soon as it became apparent that $\mathrm{RBC}$ was not covered.

4.2.7 'Reflection of public priorities' may mean, for example, that more attention would be paid to companies writing personal lines than might be justified by their position in the economy.

4.2.8 A battery of tests may cope with diversity better than a formula, but a precise, single-figure formula may be more effective at enabling the regulator to intervene.

4.2.9 A flexible formula may enable a better response to changing situations than a fixed one, but this then poses the problems of who should keep the formula up to date and what time scale should reviews be subject to.

4.2.10 Not all financially significant factors can be included in a formula. The decision about what to include is a pragmatic one. Ad hoc private adjustments may be applied by the regulator for other factors.

4.2.11 The RBC would need to integrate with the asset and liability valuation regime, in particular with the issue of whether reserves were discounted and whether equalisation reserves were held.

4.2.12 The approach of Lloyd's to RBC has been to aim for an equalisation, relative to the Names' premium income limits, of the expected charge to the Lloyd's Central Fund. Given that Names' contributions to the Central Fund are assessed in proportion to their premium limits, this aim makes sense. For the regulator of insurance companies in an environment where guarantee funds like the Policyholders' Protection Board exist, a similar aim is appropriate. The PPB does not, however, respond to all policyholder claims in all insurer insolvencies. Nevertheless, the presumption that the expected policyholder deficit should be equalised relative to premium income is a rational approach. 


\subsection{RBC Components}

4.3.1 The formula should comprise the following RBC components:

- asset risk;

- premium risk;

- reserve risk;

- credit risk;

- growth risk;

- catastrophe risk;

- currency mismatch risk; and

- expense risk.

4.3.2 Asset risk would include separate risk charges for each asset type (other than reinsurance recoveries and agents' balances), which would be related to market value volatility as well as the risk of default. The list of asset categories in the present DTI returns could be used. There needs to be a covariance factor across asset types, reflecting the benefits of asset diversification. If use is made of derivatives, the formula should look through to the underlying exposure. An asset concentration adjustment to allow for exposure to specific entities could be used, rather than the current admissibility limits.

4.3.3 Premium risk would cover the risk of business being written on unprofitable terms, and should recognise the existence of pricing cycles. At the least, a view over a historical period long enough to cover a complete cycle should be taken. The paradox that premium-based charges are relatively low when premium rates are low (and the charges most needed) is difficult to address, since it is difficult to assess at what point in the cycle the present moment stands.

4.3.4 Separate risk charges are required for different classes of business. The authors feel that subdivision by class should be more detailed than DTI accounting classes. However, too many subdivisions would entail additional complexity without commensurate benefit. There needs to be a premium risk covariance factor, reflecting the benefits of diversification by class of business. The benefit of outwards reinsurance should be included, allowing for differences between types of reinsurance.

4.3.5 Reserve risk would cover the risk of reserves proving inadequate, with due allowance for the time value of money. Separate risk charges are required for different classes of business, again with the benefit of outwards reinsurance of different types included.

4.3.6 Credit risk would cover the risk of default in respect of reinsurance recoverables and agents' balances, to the extent that these have not been written off. Separate risk charges are required for companies still trading and companies in liquidation or administration and for debtors by age of debt. Risk charges should be related to outstanding payments and recoveries, including IBNR recoveries, and the spread of risk across debtor companies.

4.3.7 Growth risk would cover the additional risks attaching to companies which grow abnormally rapidly or slowly in one or more lines of business. This 
risk element should only be included if it can be demonstrated that abnormal growth leads to risk that is not captured by other factors.

4.3.8 The catastrophe risk charge would be related to the company's maximum probable loss from a natural catastrophe in certain geographical locations and the estimated frequency of catastrophes in these areas, including an allowance for multiple events.

4.3.9 The currency mismatch risk charge would be related to the extent of currency mismatch between the assets and the liabilities, and would require companies to quantify this.

4.3.10 The expense risk would cover the risk of the inflationary increase of expenses.

\subsection{Calculation of Risk Charges}

4.4.1 An attempt should be made to use a statistical distribution for each $\mathrm{RBC}$ component. In practice, some distributions (e.g. asset risk) can be closely fitted statistically, while others (e.g. credit risk) will need to be based substantially on judgement, following examination of the available data.

4.4.2 Statistical distributions should be chosen from a limited range (e.g. Normal, log Normal, Gamma), and different types of distribution could be used for different types of risk, because some risks are more symmetric than others.

4.4.3 The risk charges could be based either on a percentile of the statistical distribution used or on a criterion for the expected excess amounts.

4.4.4 All risk charges could be based, at least initially, on the experience of, say, the last ten years for the market as a whole, using industry statistics, but with allowance for known changes in market terms and conditions. Basing the risk charges on past experience will be easier for some risk elements than for others. For example, more data are available for asset risk than credit risk. However, the risk charge for all elements should be related in some way, even if very approximately, to past experience.

4.4.5 Adjustments to reflect the experience of individual companies should be avoided, since this could lead to the presumption that past releases of reserves indicate that future releases of reserves are probable.

4.4.6 Adjustments should then be made, based, if necessary, on judgement, to reflect:

- exceptional events of the last ten years which are unlikely to be repeated to the same extent in the future, for example mortgage indemnity losses; and

- areas where past experience of variability may not be a good guide to future variability, for example reinsurance bad debts and natural catastrophes.

4.4.7 The absolute value of a RBC formula will be a political decision, reflecting, to some extent, what the market will stand. Consequently, it will be more important to get the relativities right between different risk charges.

4.4.8 The approach outlined in $\mathbb{\pi} 4.4 .7$ should considerably simplify the calculation of the covariance adjustment factor. Given that the absolute level of 
RBC will have to be determined judgementally, the authors believe that it is fruitless to consider covariance adjustments that relate to correlations between risk elements that may apply approximately uniformly to all companies, for example those between asset risk and premium risk. We believe, however, that it is important to focus on the need for covariance adjustments for correlations which differ between companies, and where there is scope for individual companies to diversify their portfolios of risk.

4.4.9 The principal areas for possible diversification appear to be diversification by asset type and by class of business (at least in respect of future claims). The reserve risk relates more to the company's reserving processes, and can, therefore, be considered a systematic risk, which is unlikely to be substantially diversified by having a spread of classes of business.

\subsubsection{We suggest therefore that:}

- there should be no overall covariance adjustment factor; and

- separate covariance adjustment factors should apply within the asset and premium risk charges, but not within the reserve risk charge.

4.4.11 The asset risk covariance adjustment factors could be based on simple pairwise correlations between asset types, rather than on multiple regression techniques. The benefit of diversification among asset counter-parties should also be considered. The same pairwise correlation approach could be used for the premium risk covariance adjustment factors between classes of business.

\subsection{Testing}

4.5.1 In the authors' view, there is little value in testing the absolute value of the formula, for the reasons outlined in \$4.4.7. We believe, however, that the formula should be tested to check if the relative values are appropriate for different types of company.

4.5.2 We suggest that the testing should be carried out on companies with different characteristics as follows:

— size (large/medium-sized/small);

- growth rate (rapid/slow);

- long-tail/short-tail;

- product range (mono-line/multi-line);

- territory (U.K./multinational);

- reliance (past and present) on outwards reinsurance (light/heavy); and

— asset portfolio (concentrated/diversified).

4.5.3 Testing will require the use of reliable data. There have been inconsistencies in the way in which certain published accounting data have been treated by different companies and across different accounting periods, for example in the treatment of discounted loss reserves. While the relevant data are in the public domain, only the DTI will be aware, at a global level, of all these inconsistencies, and is, therefore, in the best position to deal with them. 


\section{CAPITAL Allocation}

5.1 In this section we consider reasons for allocating total capital to business units, the difficulties that arise in capital allocation, how such an allocation could be assisted by $\mathrm{RBC}$, how relative performance can be measured using capital allocations, and describe some return on capital pricing techniques. This updates and extends the work of Green et al. (1991), in the light of RBC. In contrast to the other sections of this paper, we switch to the perspective of the shareholder rather than the policyholder or regulator. In particular, we consider how management can set performance targets in order to meet shareholders' expectations or requirements.

\subsection{Reasons for Allocating Total Capital to Business Units}

5.2.1 Subject to the restrictions imposed by trust funds and other legal requirements, all assets of a corporate legal entity are available to meet any of its liabilities. There is, therefore, a strong sense in which capital cannot be allocated to business units within a company. Going 'into the red' with one bank account is not synonymous with going bankrupt.

5.2.2 Despite this, an insurance company's management often finds it a useful discipline to behave as if the business units were miniature insurance companies, having to manage their affairs with a notional allocation of the company's overall capital. In this context, a 'business unit' represents some management grouping, and could be a subsidiary, branch, line of business, distribution channel or even a major client or intermediary relationship.

5.2.3 Capital allocation is often intended to focus local managers' attention on underwriting as an investment decision. Managers' decisions to underwrite an individual policy or to be in a certain line of business commits the company's capital to all the potential costs that will arise, including those of claims and their administration, in the same way as an investment decision commits capital to the investment project.

5.2.4 The returns from taking an underwriting decision are represented by the premiums that are received over time, less the associated claims and other costs, that flow from the underwriting decision. These returns will include all future renewal premiums from existing customers, as well as the option to sell different types of policy in future to the customer base. In financial economic terms, this is the future growth potential.

5.2.5 In a limited liability company, the capital committed by the underwriting investment decision is usually the entire worth of the company, including the value of the options described above. There is a gearing effect, however, in that the value of these options may be very much reduced if the returns obtained from the existing underwriting investments prove to be low (i.e. the company makes substantial insurance losses).

5.2.6 In the context of Lloyd's, with unlimited liability for individual Names, the capital committed is not easy to measure, and the value of the options is 
complicated by the impermanence of the capital base. However, the inability of a small number of Names to meet their Lloyd's obligations would not necessarily, of itself, adversely affect customer goodwill as a whole.

5.2.7 The benefits of capital allocation are:

- to give local managers a sense of the financial requirements of the company or group;

- to indicate to local managers the extent to which they are permitted to put the company or group's capital at risk without reference to corporate management; and

- to give a reasoned way of measuring, and perhaps rewarding, performance relative to the risks undertaken.

However, capital allocation is not the only way of achieving these benefits, and, indeed, should be additional to, rather than instead of, the normal controls necessary to ensure the competence of local management.

5.2.8 The practical and theoretical difficulties that arise in allocation of capital include:

- the lack of additivity of capital allocation, depending on the criteria used (see I5.3.3);

- the irrelevance of capital allocation to cash flows and overall performance (see Bride \& Lomax, 1994, Iा 2.2.1-2);

- gaining acceptance of the allocation, given that it is notional and, to some extent, arbitrary;

- how much capital to allocate; and

- to what level of detail to allocate.

5.2.9 In addition, it is important for corporate management to be aware of the possibility that treating business units as miniature insurance companies could lead to decisions taken at the local business unit level that, while making sense in the context of a small insurance company focusing on a single line of business, do not make sense in the wider context. Corporate management should, therefore, intervene, as necessary, to avoid this.

5.2.10 One example of this is individual underwriting managers either not' accepting large risks or buying reinsurance protection to too low a level, without regard to the benefits of corporate or group capital strength. This probably happens at Lloyd's, where the underwriter of an individual syndicate cannot, almost by definition, consider the benefit of diversification for the Names on that syndicate. As a result, some Lloyd's syndicates may have bought too much reinsurance for the majority of their members, much of this from other syndicates or London Market companies, providing a demand for reinsurance that encouraged the development of the London Market Excess of Loss (LMX) spiral (the phenomenon in which, particularly during the late 1980s and early 1990s, major losses - such as that from the North Sea platform Piper Alpha - circulated 
around the market, continuing to develop long after the original losses had been settled, leaving some underwriters with much greater exposures to these losses than they had anticipated).

5.2.11 As a result of 'group strength', risks written at the local level may, therefore, be large in relation to the capitalisation of the local business unit. The demand by local underwriting managers for protection, rather than by buying external reinsurance, may be met by a form of notional internal reinsurance (for performance measurement purposes). These arrangements may extend beyond traditional per-risk or catastrophe excess of loss reinsurance to whole account stop loss arrangements, and they may be either formalised or relatively informal. Such arrangements enable the group to monitor and control exposures that are too great to be borne by the capital allocated to the individual business unit in isolation (cf. I5.2.7).

\subsection{How Capital Allocation could be assisted by RBC Concepts}

5.3.1 By analogy with the discussion in $\$ 4.2 .12$, a rational requirement of a capital allocation to business units would be to equalise (relative to a base such as premium income) the expected value of the charge on the other business units that would occur should the allocated capital for the business unit in question prove inadequate. This approach would be analogous to the 'expected policyholder deficit’ conceptual framework described in $\$ 4.2 .5$.

5.3.2 This would entail the use of a RBC formula applied to each business unit, relative to a specified criterion. $\mathrm{A} \mathrm{RBC}$ formula applied to the entire company would generate:

- the $\mathrm{RBC}$ required by that formula; and

- the surplus or deficiency of actual capital compared to this required RBC.

5.3.3 However, the total capital 'required' (relative to a specified criterion) for a series of stand-alone companies writing unrelated business is likely to be significantly more than the capital 'required' (relative to the same criterion) for a company formed from the merger of these individual companies. If this common criterion can be used for marketing purposes, then the merged company, therefore, has a marketing advantage in each of its market segments, compared with the notional stand-alone company, simply by virtue of its capital strength, let alone any economies of scale.

5.3.4 In general, the sum of the 'required' amounts of capital for each business unit will not equal the 'required' capital for the company as a whole. Neither will it equal the actual capital for the company as a whole, unless the criteria are set in this way.

5.3.5 The gap between:

- the sum of the 'required' amounts of capital for each business unit; and

- the actual capital for the company as a whole; 
may be positive or negative. Whether an attempt should be made to bridge the gap needs to be considered.

5.3.6 In any event, the common methods of allocation of actual capital to business units, simply pro rata to premiums written (or to other measures) will not necessarily give an equal relative expected charge to the other business units.

5.3.7 One approach may be to ignore the gap referred to in $\pi 5.3 .5$, and allocate (notional) capital equal to the 'required' capital on a stand-alone basis. This creates a difficult debate about the status of the 'spare' capital (if any), and, given that the spare capital is still at risk, how the providers of the spare capital are to be rewarded (see Bride \& Lomax, 1994, 77.4 ).

5.3.8 An alternative approach, which takes account of the total company and the risks that can be diversified within it, is to consider the marginal RBC for each business unit. That is, each business unit is allocated the difference between: - the capital required by the company with that business unit; and

- the capital required by the company, using consistent criteria, without that business unit.

In doing this, specific assets and liabilities need to be allocated to each business unit.

5.3.9 This method of allocation creates other difficulties:

- The marginal required capital for one business unit could be negative in certain circumstances. Should that business unit be given full credit for this? If not, how, if at all, is the credit to be spread among business units?

- The sum of the amounts of marginal required capital probably will not equal the required capital of the entire portfolio, unless the portfolio is built up by adding business units step by step. How, if at all, should any resulting surplus or deficiency be allocated?

- If the portfolio is built up step by step, as above, the marginal required capital may depend on the order in which business units are added to the portfolio. Which of the several amounts for the marginal required capital should then be chosen?

5.3.10 One further complication arises from the fact that there is a distinction between 'required' RBC and capital 'required' for market perception. Often there will be a 'marketing top-up' of capital needed (see Hitchcox, 1995).

5.3.11 Then, supposing that the business units are allocated marketing top-up capital in addition to the required $\mathrm{RBC}$, we can ask whether the return demanded on this top-up capital may be reduced in comparison with that which would be demanded simply on the required RBC.

5.3.12 The greater the over-capitalisation, the lower the return on capital that should be required. Under-capitalisation of a business unit or subsidiary, where the corporate $\mathrm{RBC}$ requirements are more stringent than the market perception, needs more fundamental consideration.

5.3.13 Return on capital can be measured in many ways, but, for an annual 
exercise, it is necessary to consider the changes in the liabilities and assets over a one-year period, at present/market values, and, importantly, to consider the changes in the required capital over that period. Since not all business will have run off during the year, it is important not to release the capital on the outstanding reserves in this calculation.

\subsection{Return on Capital Pricing Techniques}

5.4.1 This section gives two different examples of ways in which RBC ideas have been, or could be, used in practice to determine pricing strategies. The two methods can be described as a 'top-down' approach and a 'bottom-up' approach.

5.4.2 A top-down approach has been described in Hitchcox (1995), and, essentially, starts with a computation for each business unit of the 'underwriting capital base' (UCB). This consists of the underwriting and reserving risk charges, an investment risk charge and a strong growth charge (where necessary), which could be calculated using an approach similar to the U.S. RBC formula. There is also a covariance factor adjustment, calculated at the group level, but which needs to be allocated to each business unit for practical purposes. Though this allocation may, in practice, take the form of an across-the-board percentage reduction, it should, in principle, reflect the degree to which the risks of the business units are diversified within the company.

5.4.3 Next, the corporate 'return on equity' (ROE) targets are applied to the UCB to obtain the target profit by line of business. The ROE targets may be expressed as a multiple of, or an add-on to, the risk-free rate considered to be appropriate (e.g. U.K. government bonds of an appropriate duration for U.K.domiciled risks). Whether these ROE targets should also vary according to the volatility of the line of business is a debatable point. It may often be argued that there is no need for this variation if the UCB has already taken relative volatility into account. Converting different volatilities into appropriate risk loadings is not easy to specify consistently.

5.4.4 The effect of investment income on the funds is allowed for as a credit. How much to attribute to each line of business will depend on the relevant interest rates, proportion of funds that are available for investment and the requirement to 'borrow' funds (from another business unit) in order to mitigate valuation strain. This approach recognises that the underwriting managers have little influence over the actual investment performance, and they will, in effect, be credited with earning the risk-free rate on the funds generated by the business written.

5.4.5 The result of these calculations leads to a 'target operating ratio' (TOR) for each line of business, which then needs to be adjusted to take account of outwards reinsurance costs and internal expenses that are deemed to be outside the control of the underwriting managers. Having deducted these costs, the 'target underwriting ratio' (TUR) is obtained. This ratio expresses the acceptable level for the ratio of claims and acquisition costs as a percentage of inwards premiums, 
over each of which the underwriting manager has some control. The TUR, therefore, directly relates underwriting targets to financial targets.

5.4.6 One problem with this approach is that, in setting the UCBs, on which the targets ultimately depend, those corporate managers who set the targets must assume that the nature of the gross business within the business units and its outwards reinsurance protection will remain unchanged, or, alternatively, they must anticipate any such changes. An individual underwriting manager may, therefore, find it easier to achieve these targets by accepting riskier business than anticipated, since the most sophisticated competitors will, presumably, be adopting appropriately stringent targets for this riskier business. This problem can be compounded if there are significant changes in the cost and availability of reinsurance cover, such as happened in the early 1990s. In these circumstances, the basis for the UCBs would need to be reconsidered.

5.4.7 Another problem is that the approach does not link assets and liabilities directly. Sometimes the fluctuations in asset values are independent of the fluctuations in liability values, but sometimes the fluctuations in asset and liability values are correlated, for instance in being linked to economic inflation.

5.4.8 A third problem lies in the allocation of capital between past and present. Capital will still be required for a 'retired' line of business while it is running off. The decision to cease underwriting a particular line of business is, itself, an investment decision, and, indeed, is a valuable option. The top-down approach needs to consider whether ROE targets are appropriate for any such lines, and if so, what their required ROEs should be. This consideration will depend more heavily on the reserve risk and the margins, if any, in the reserves, such as the extent to which they are not discounted.

5.4.9 The second example is the bottom-up approach. Here, each block of business is considered separately, when it is written, with its specific characteristics being explicitly taken into account.

5.4.10 The first step is to assess the expected losses and loss expenses and the aggregate statistical distribution of losses and loss expenses. The first component in the measurement of the capital required to support the business is related to the variability, taking into account only the downside potential. This could be measured by the downside semi-deviation of the aggregate loss distribution, which is analogous to the usual standard deviation, but taking into account only the set of outcomes in which the present value of losses and loss expenses exceeds the present value of premiums.

5.4.11 The second component in measuring the required capital is the capital needed to meet the demands of the market and regulators. This capital to meet market demands will depend on the line of business, and, currently, is often expressed as a percentage of premium. In time, however, a form of RBC may become the accepted means of determining 'market demand capital'.

5.4.12 Finally, capital will be required over the lifetime of the business, as it is run off. It is, therefore, necessary to consider the duration over which claims will be paid out and over which reserves need to be held (and therefore over 
which there remains uncertainty). There are many measures for this element, for example by the mean payout term of losses or the difference between discounted and undiscounted expected losses. Also, the larger the reserves and the longer they are held for outstanding losses, the greater the asset risk. This, together with the nature of the assets needed, should be allowed for in the measurement.

5.4.13 The result of these calculations is a series of indicators of the components of the required capital, and it is, therefore, necessary to apply a formula to convert these indicators into a single figure for the capital allocated to the line of business.

5.4.14 As with the top-down approach, the required ROE is selected, and the premium rates can then be set so that, on an expected basis allowing for stochastic variation, this ROE is achieved.

5.4.15 There are many difficulties with the bottom-up approach. First, it requires detailed analysis of each line of business and many judgements of the parameters. Second, any formula for deriving the allocated capital from the components is subjective. Third, the sum of the capital allocated in this way may not equal the actual capital or RBC for the company as a whole.

5.4.16 The top-down and bottom-up approaches are very different, and it is not easy to reconcile the two. However, the formula required in the bottom-up approach (see 95.4 .13 ) can be established pragmatically, after analysing the portfolio of business and trying various combinations, aiming for a reasonable 'fit' to the top-down capital allocation. In either case, an iterative discussion process is probably necessary in order to achieve an allocation methodology acceptable to all areas of responsibility in the company.

5.4.17 The discussion process may, indeed, be the most valuable part of the exercise. Hitchcox (1995) claims that the approach he describes has added clarity to the assessment and management of underwriting performance within one particular company.

\section{INSURANCE SUPERVISION}

6.1 In this section we consider the role of the regulator and the various approaches that could be adopted to assist in non-life insurance supervision, including:

- the old U.S. minimum capital rules;

- the existing E.U. solvency margin rules;

- RBC formulae;

- dynamic solvency testing;

- statutory professional involvement; and

- the market solution.

\subsection{Formula-Based Approaches}

6.2.1 Before RBC was introduced, the old U.S. minimum capital rules were 
a flat dollar amount per company. This was easy to apply, especially in a startup situation. However, after a company was established and had grown, the initial minimum capital was likely to be woefully inadequate, and would not necessarily reflect the needs of business written or planned.

6.2.2 The existing E.U. solvency margin goes a stage further than the old U.S. minimum capital rules. To simplify slightly, it applies fixed percentages, on an annual basis, to recent premiums and incurred claims, taking the higher of the resulting two amounts. The required capital, with this approach, would grow with the company, but could still be inappropriate, as it takes into account none of the specific features of the business the company has written, or will write in the future.

6.2.3 The E.U. solvency margin suffers from similar drawbacks to RBC, such as the fact that premiums are a poor measure of exposure, so that less capital may be required when exposures actually increase. Likewise, under-reserving would, in the short term, lead to a reduced capital requirement under the E.U. solvency margin rules, just as for $\mathrm{RBC}$.

6.2.4 The E.U. formula applies a percentage factor to the written premiums (or one to incurred claims if this results in a higher figure), and these amounts may, up to a point, be reduced by the ratio of net to gross incurred claims. Comparing with the RBC approach, there is no attempt to distinguish between different classes of business, no attempt to distinguish between companies that have different reserves or 'tails' from past written business, no attempt to load for possible reinsurer failure beyond that recognised by companies in their accounting provisions and no attempt to measure the risk that is due to holding investments in other than risk-free securities.

\subsection{Statutory Professional Involvement and Dynamic Solvency Testing}

6.3.1 Statutory professional involvement, including professional certification of financial strength (not just technical reserves), is one option that could be considered as an alternative, or supplement, to a formula-based approach to capital requirements. Under this option, the insurance company's management would have the responsibility of ensuring that a person, recognised as competent in the area, would regularly review the company's business operations and provide an opinion to the management or to regulators on the financial strength of the company.

6.3.2 This approach has been adopted as one of the major elements of the supervision of the life and pensions industries in the U.K. The periodic actuarial inspections are framed within guidelines agreed between the actuarial profession and the regulators.

6.3.3 Statutory professional involvement is more flexible than a formulabased approach. It has some comparative disadvantages, including potential inconsistency of application. This could, however, be addressed by the appropriate professional body co-ordinating its members' work and setting and monitoring standards. 
6.3.4 This could work better than a fixed RBC formula, by enabling the specialist to take into consideration the particular circumstances of the company, including the margins (if any) in its reserves and in its premium rates, as well as the degree of matching of its assets to its liabilities and its exposure to aggregation risks. Such a system could include 'dynamic financial analysis', which would require an economic/financial model of the company to be tested under a range of adverse scenarios. This would include cash flow testing, allowing for random variations and sensitivity analysis to test the effect of key assumptions underlying reserving projections.

6.3.5 'Dynamic solvency testing' (or DST) has become topical since its proposed introduction in Canada. DST is less formalised than RBC, but is arguably a more flexible means by which the risks for individual companies can be taken into account in establishing acceptable capital levels for these companies.

6.3.6 Under DST, the insurance company's management uses a financial model of the company to visualise the consequences of the expected and a series of selected adverse future scenarios on the ability of the company to meet its ongoing obligations.

6.3.7 This has the advantage that the risks to each company can be assessed more accurately than in a blanket formula. However, it has the disadvantage that it is complicated to apply, requires resources that may not be available to all companies, may be applied inconsistently and is likely to be time consuming.

6.3.8 The Canadian Institute of Actuaries has developed guidance on DST, and the paragraphs below are paraphrased from the CIA Committee on Solvency Standards for Financial Institutions (1994).

6.3.9 In DST, the prime purpose of the actuary's investigation is to enable him or her to provide advice about trends in surplus and threats to the company's solvency, and to identify courses of action which may mitigate the threat. The investigation should explore the sensitivity of the company to changes in its economic environment. The information will allow management to manage the company better and to protect the policyholders and claimants against future losses due to insolvency.

6.3.10 The actuary should establish a set of criteria for solvency appropriate to the company, and base the investigation and report on these criteria. The actuary's investigation of the company's solvency should consider the past and present financial positions and future financial condition of the company and the sensitivity of surplus to changes in experience and management policies. Investigations should include the past and current portfolio and anticipated future writings.

6.3.11 The investigations should normally include a review of the financial results, surplus levels and operations of the five most recent years and projections of the company's operations under a variety of scenarios. These scenarios should include a base scenario, using the actuary's best estimate of future experience (normally consistent with the company's current business plan), and a number of 
adverse scenarios designed to investigate the company's sensitivity to various threats.

6.3.12 It is unlikely that the actuary will be able to determine whether the company has a significant probability of failing any specified solvency test unless he or she carries out some sensitivity testing. The main value of DST is, therefore, in the sensitivity testing. In determining the areas of greatest exposure to risk, it is important for management to be able to set a business plan which has a high probability of success. Even well-capitalised companies do not wish to run a risk of a downgrade in rating that could have been avoided if the risks had been better known. The sensitivity testing helps the actuary to gain a better understanding of the company as a whole, and how it may respond as the market place changes. Trying a variety of scenarios is useful in finding actions to mitigate a perceived exposure to risk.

6.3.13 One of the issues that particularly needs to be considered regarding scenario testing is understanding the effect of individual factors on solvency levels, which may not be linear. The most important factors to consider are those considered most likely to apply to the company. Also, the effect of combinations of factors may not be straightforward. There are often interactions in the output and interrelationships between the inputs. The dynamic aspect comes into play when considering what actions can be taken to mitigate the adverse impact of certain scenarios.

6.3.14 The period covered by the investigation needs to be considered carefully. Just as in a game of chess the best players look many moves ahead, so in DST it may be necessary to forecast over a period beyond the company's planning horizon, although the validity of long-range projections may be questionable.

6.3.15 The purpose of the DST report is to warn management and the regulator about material, plausible and imminent threats to the company's solvency and, where possible, describe courses of action for the company's consideration in addressing the threats.

6.3.16 The CIA exposure draft included a list of suggested items for scenario testing. These included:

- reinsurance programme;

- loss ratio;

- expense level;

- volume;

— unpaid claim liabilities; and

- investment performance.

\subsection{The Market Solution}

6.4.1 A consequences of not having a RBC or other formula for regulatory purposes is that it would be left to the market to judge the security of individual companies.

6.4.2 Rating agencies say that $\mathrm{RBC}$ is not a threat or an alternative to 
security rating. As they put it, $\mathrm{RBC}$, of itself, is a relatively blunt instrument for security a.

6.4.3 Standard \& roor, for example, have analysed the insurance industry experience in the U.S.A. since 1990 , to test whether RBC or any other regulatory system is a good predictor of future solvency. RBC proved to be only $57 \%$ accurate, while traditional premium to surplus ratios gave a marginally higher $60 \%$ accuracy, although this improvement may not be statistically significant. Using the NAIC's diagnostic set of ratios, prediction accuracy rose to $72 \%$.

6.4.4 Standard \& Poor also analysed 2000 insurance companies in the period 1988-91, and identified the main reasons why insurance companies became insolvent. This analysis showed that in only $32 \%$ of cases was capitalisation the primary factor. Other factors that were important were liquidity, also $32 \%$, profitability, $24 \%$ and risk spread, $12 \%$.

6.4.5 Rating agencies, typically, look, not just at the amount of capital, but also at management and corporate strategy, performing a review of the business and analysis of the operations, and at the company's liquidity and its financial flexibility, i.e. support from its parent or access to reinsurance.

6.4.6 However, the question whether RBC will lead to better insurance regulation should be seen as distinct from the question of how accurate $R B C$ is as a predictor of future solvency for insurance companies.

6.4.7 The market approach may well be better as a pure measure of security, but rating agencies, as such, have no powers to force an insurance company to take corrective action or to cease trading altogether, as a regulator would. Also, managers of companies with problems, be these companies within the insurance industry or not, may be tempted to take additional risks in order to gain time to turn the company round. If managements have the threat of regulators closing their companies down, and, perhaps, deeming the managers not fit and proper persons, this may encourage a 'rescue culture', so that companies can be put into orderly and solvent run off.

\subsection{The Role of the Regulator}

6.5.1 Adequate capital is important, but is only one of the regulator's objectives. Others include fitness of management and the adequacy and suitability of reinsurance. for:

6.5.2 The regulator requires a decision rule that is objective and consistent

- when to examine a company more closely;

- when to take action against a company; and

- what action to take.

6.5.3 Any formula is imperfect, since events are not entirely deterministic. As a statistical test, therefore, any decision rule will be prone to 'type 1' errors (i.e. failure to spot or intervene in a troubled company) and 'type 2' errors (i.e. unnecessary work or intervention). 
6.5.4 Generally, type 2 is regarded as less serious than type 1 , since the prime aim is to protect insureds against potential insolvency, but type 2 errors are undesirable, as they create:

- for the regulator, a diversion of resources, leading either to genuinely troubled companies not being dealt with, or over-costly supervision, or both;

- for the owners of the insurance companies concerned, loss of trade; and

- for the consumer, increased cost of insurance and a weakened perception of the market.

6.5.5 The regulator's priorities should, therefore, be to minimise, or at least limit to an 'acceptable' level:

- the number of insolvencies;

- the number of people adversely affected by insolvencies;

- the cost of insolvencies;

- the predictable or anticipatible insolvencies; and

- the cost of actions to restrict insolvencies.

6.5.6 However, the regulator needs to bear in mind 'regulatory arbitrage'. That is, if supervision is thought to be unsound or too strong, insurers or their customers may go elsewhere.

6.5.7 Action by the regulator can include:

- faster examination of the company's information;

- more detailed examination of information available;

- asking the company for additional information;

- requiring the company to prepare a plan for the restoration of a sound financial position;

- requiring the company to take specific actions;

- direct intervention in the affairs of the company; and

- winding up the company.

6.5.8 With a strong formula, the regulator would need discretion not to intervene at the specified action levels if, in particular circumstances, the formula is too harsh. With a weak formula, the regulator needs power to intervene on grounds of financial weakness in particular circumstances, even though the statutory margin may be covered.

6.5.9 Action by the regulator can include informal requests and hints to management. If this has statutory backing, the company knows that the regulator can enforce requests or impose more draconian measures, so this can be very effective and flexible, leaving formal enforcement as a last resort. The mere indication that the regulator is taking an interest can have an effect.

6.5.10 For many companies, especially those not writing high-risk business, the greatest risks relate to potential mismanagement. From an outside viewpoint, the scope for mismanagement always appears greater than the internal 
management would accept. The regulator will, therefore, often need to impose greater capital requirements than the company considers necessary.

6.5.11 Any RBC formula which mandates or permits specific action by the regulator will be in the public domain. It is not obvious why the results of this should be confidential.

6.5.12 On the other hand, a RBC formula used to determine the regulator's internal priorities need not, necessarily, be made public. The formula may depend on 'soft' information, which may be difficult to publish. An undisclosed formula should not give rise to undesirable behavioural changes.

\section{CONCLUSIONS}

\subsection{Understanding what the Formula actually is}

7.1.1 RBC is an attempt (but only an attempt) at a better, objective measure, than previous rules were giving, of the capital an insurance company needs, taking account of its own unique set of circumstances, to maintain a fair and adequate security margin for companies across the insurance industry.

7.1.2 Capital is required in order to absorb the inevitable risks inherent in writing insurance business. In this context, 'risk' is viewed as the variability or uncertainty in the economic values rather than the probability of an economic loss of a particular size. RBC is, therefore, an attempt to relate the capital to the risks of individual insurance companies.

7.1.3 In contrast with companies in other industries, insurers rarely run out of cash before their assets become insufficient to meet their liabilities. RBC standards can provide insurance industry regulators with an early warning of problems ahead for insurance companies, and provide trigger points for various levels of action by the regulators.

7.1.4 RBC, therefore, will provide a public measure of strength for the insurance industry. In a U.K. context, this accords with the principle of 'freedom with disclosure' adopted by the DTI as regulator of the industry in the U.K.

7.1.5 RBC should be designed to encourage good behaviour and discourage bad behaviour among insurance company management. The introduction of RBC standards may (or may not) increase the overall amount of capital required in the industry, but, almost certainly, there will be a re-distribution of capital.

7.1.6 From the regulatory point of view, solvency of an insurance company is viewed in terms of a run-off situation - does the company have enough assets to meet its outstanding and potential liabilities to policyholders if it ceases trading now or in the near future? From the point of view of an insurance company's management or shareholders, the important issues are seen in the context of a going concern - what are the criteria for an adequate return on capital to be achieved in continuing to write insurance business?

7.1.7 RBC should help focus management on risks and the possibilities and limitations of their actions to control risks. The application of the RBC approach 
to the question of capital allocation should assist insurance company management to obtain a fuller appreciation of the financial dynamics of the business.

7.1.8 There is a conflict between security for policyholders and return to shareholders, which is similar to the conflict between the equity- and debt-holders of a company in any industry. Financial economists argue that the value of a company's total assets is the sum of the value of its equity and the value of its debt. Raising shareholder value must, therefore, they argue, mean lowering the value of debt. It is the regulators' role to judge, from the political perspective, where the balance for these conflicting interests should lie.

7.1.9 No system of capital adequacy can meet all possible situations. The events at Barings appear, to many observers, to have been due to a failure of internal management controls, rather than insufficient capital as such. These situations do not necessarily mean that no attempt should be made at formulabased regulations on capital adequacy. They simply mean that these should not be the only means of regulating financial services.

7.1.10 Any RBC system will be able to provide rough justice only. An important issue for regulators is to provide a 'level playing field' and to ensure that poorly performing insurers can, and do, cease trading solvently, and maintain an orderly run-off, which should then reduce the costs of insolvency by limiting the impact of bankruptcies on guarantee funds like the Lloyd's Central Fund and the Policyholders' Protection Board's levies.

7.1.11 Regulators are also interested in providing fair competition on price and enabling policyholders' reasonable expectations to be met. It is in the interests of the insurance industry that this should happen, as such factors should bring credit to the industry, whereas insolvencies bring discredit.

7.1.12 Shareholders' perspectives, too, are that capital allocation should be related to their exposure to risk, which can be viewed as the potential for a business to use up shareholders' capital. Insurance company shareholders, like any other investors, are able to operate in relatively free and efficient capital markets, where the taking of risk has been historically rewarded by means of an additional return above the risk-free return provided by 'safe' investments (i.e. in government securities). A free and efficient financial market should, in theory, adjust the traded value of insurance companies to meet the market's risk/reward criteria, and deliver a fair return to shareholders, commensurate with the inherent market or undiversifiable risk.

\subsection{Is a Bad Formula better than no Formula at all?}

7.2.1 The U.S. and Lloyd's RBC formulae cannot be perfect. They are definitely not substitutes for good management and controls. However, despite the drawbacks of a complicated formula, one should never be simple, standard or static.

7.2.2 The U.S. RBC formula is aimed at providing a reasonable degree of approximate justice between competing companies. It sets levels of intervention, and, within those levels, provides a degree of discretion to regulators, who can 
use their judgement in marginal cases to consider the individual facts of each company.

7.2.3 One study in the U.S.A. has concluded that, by and large, companies that failed the RBC test are those that should have failed. In a sense, therefore, RBC adds nothing new. Indeed, other studies have concluded that RBC is a relatively poor predictor of company failure compared with other means of examining companies, such as considering rating agencies' ratings and the NAIC's own diagnostic ratios.

7.2.4 However, one of the main benefits of a RBC formula is that it concentrates the mind of management on risk. It forces companies to measure risk, which is a precondition for being able to control risks.

7.2.5 The RBC formula is generally reasonable, although no formula can be ideal in all circumstances. In a U.K. context, a similar formula would measure risk more accurately than the current E.U. solvency margin. Further measures could be appropriate, such as requiring companies to carry out dynamic financial analysis and to obtain professional opinions on their financial strength and key areas of sensitivity.

7.2.6 Interestingly, the banking industry now seems to be turning away from a 'one-size fits all' capital formula. The G10 Committee and the U.S. Federal Reserve Bank now seem to be favouring authorising banks to use their own internal bespoke models of risk to control and manage their exposures. All this is happening despite the events at Barings.

7.2.7 It is hoped that the European insurance regulators can learn some lessons from the U.S. insurance industry's experience of RBC and from the experiences of the banking industry. Given a formula-based regulatory system (as currently exists in the E.U.), the main issues, in the authors' view, are:

- What factors should be included or excluded from any formula?

- How are the relationships between risk factors to be dealt with?

- How public should the results be made?

- What role, if any, is there for insurance companies' internal models of risk?

7.2.8 Alternative or complementary approaches to the U.K. supervision of non-life insurers would also be worth considering. These could include dynamic solvency testing and statutory professional opinions on financial strength.

\section{ACKNOWLEDGEMENTS}

The authors would like to express thanks for the valuable comments that have been received from the scrutineers. We would also like to acknowledge the contributions by other members of the various working parties on RBC for the GISG conventions: Alan Botterill, Andrew Hitchcox, Michael Lomax, Andrew Newman, Tony Silverman, Martin White, and Walt Wright. The authors alone, 
however, are responsible for any errors, omissions or other deficiencies in the paper.

\section{REFERENCES}

In addition to the works referred to in the paper, the following list includes details of a few other publications that may be found useful for further reading on the subject.

ACTUARIAL ADVISORY COMMITTEE TO THE NAIC PROPERTY \& CASUALTY RISK-BASED CAPITAL Working Group (HaRTMan, D.G., BraithWaIte, P., BUTSIC, R.P., FEldblum, S., FitzGibBon, W.J., FlynN, D.P., FurST, P.A., KAUfMAN, A.M., LOWE, S.P., LyONS, D.K., MCCARTER, M.G. \& NELSON, D.A.) (1992). Property-casualty risk-based capital requirements - a conceptual framework, Casualty Actuarial Society Forum, Spring 1992, 211 280.

ACTUARIAL ADVISORY COMMITTEe TO THE NAIC PROPERTY/CASUALTY RISK-BASED CAPITAL WORKING GROUP (1993). Report on covariance method for property/casualty risk-based capital. Casualty Actuarial Society Forum, Summer 1993, 173-202.

AMERICAN ACADEMY OF ACTUARIES (1992). Position statement on insurer solvency. The Actuarial Update, November 1992.

AMERICAN ACADEMY OF ACTUARIES PROPERTY/CASUAlTy RISK-BASED CAPITAL TASK ForCE (1993). Report on reserve and underwriting risk factors. Casualty Actuarial Society Forum, Summer 1993, 105-171.

BRIDE, M. \& LOMAX, M.W. (1994). Valuation and corporate management in a non-life insurance company. J.I.A. 121, 363-440.

BUTSIC, R.P. (1992). Solvency measurement for property-liability risk-based capital applications. Casualty Actuarial Society 1992 Discussion Paper Program on Insurer Financial Solvency, 1, 311-354.

CIA COMMITTEE ON SOLVENCY STANDARDS FOR FINANCIAL INSTITUTIONS (1994). Dynamic solvency testing for property and casualty insurance companies. Exposure Draft of the Canadian Institute of Actuaries.

CLARKE, H.E. (1992). Capital adequacy and allocation of capital to lines of business. Institute of Actuaries' Asset Liability Convention, April 1992.

CUMminS, J.D., HARRINGTON, S. \& NIEHAUS, G. (1992). An economic overview of risk-based capital requirements for the property-liability insurance industry. Alliance of American Insurers.

D'ARCY, S.P. \& DOHERTY, N.A. (1988). The financial theory of pricing property-liability insurance contracts. Wharton School Monograph, University of Pennsylvania.

Daykin, C.D., PENTIKA InEN, T. \& PESONEN, E. (1993). Practical risk theory. Chapman and Hall.

Green, P.A.G., BRICKMAN, S.J., BRIDE, M., HitchCoX, A.N., JONES, S.M. \& LARNER, K.P.W. (1991). Report on capital allocation. General Insurance Convention, Llandrindod Wells, October 1991.

HITchсоX, A.N. (1995). Capital, profit and risk. Conference on Risk-Based Capital, AIC Conferences, London, May 4-5.

HoOKer, N.D., BotTerill, A., Hinton, P.H., HitchCoX, A.N., LomAX, M.W., White, M.G. \& WRIGHT, W.C. (1993). Report on risk-based capital. General Insurance Convention, Hinckley Island, October 1993.

HoOker, N.D., Bulmer, J.R., CoOper, S.M., Hinton, P.H., Newman, A., Silverman, A. \& WRIGHT, W.C. (1994). Capital requirements and risk-based capital. General Insurance Convention, Glasgow, October 1994.

HOOKER, N.D. (1993). Risk-based capital: note for the London Market Actuaries Group. 
INSTITUTE OF ACTUARIES (1993). Implementation of the Accounts Directive for General Insurance Companies-actuarial issues. Institute of Actuaries, August 1993.

JOINT ACTUARIAL WORKING PARTY (1993). Risk-based capital report. Institute of Actuaries and Faculty of Actuaries.

KAUFMAN, A.M. \& LIEBERS, E.C. (1992). NAIC risk-based capital efforts in 1990-91. Casualty Actuarial Society 1992 Discussion Paper Program (Insurer Financial Solvency), 1, 123-178.

LewiN, C.G., CARNE, S.A., DE RivaZ, N.F.C., HALl, R.E.G., MCKelVeY, K.J. \& WILKIE, A.D. (1995). Capital projects. B.A.J. 1, II, 155-330.

LLOYD'S OF LONDON (1995). Risk-based capital for Lloyd's: a consultative document.

MOHL, J. (1993). Risk-based capital: The unknown crisis. Actuarial Review, February 1993.

NATIONAL ASSOCIATION OF INSURANCE COMMISSIONERS (1993). NAIC property/casualty riskbased capital formula : exposure draft, 28 June 1993.

NEEDLEMAN, P.D. \& ROFF, T.A. (1995). Asset shares and their use in the financial management of a with-profits fund. B.A.J. 1, 603-688.

PENTIKAINEN, T. (ED.) (1982). Solvency of insurers and equalisation reserves. Insurance Publishing Company, Helsinki.

REDMAN, T.M. \& SCUDELlaRI, C.E. (1992). A new look at evaluating the financial conditions of property and casualty insurance and reinsurance companies. Casualty Actuarial Society 1992 Discussion Paper Program (Insurer Financial Solvency) 10-13 May, 2, 867-917.

RYAN, J.P. \& LARNER, K.P.W. (1990). The valuation of general insurance companies. J.I.A. 117, $597-669$. 


\section{ABSTRACT OF THE DISCUSSION}

Dr N. D. Hooker, F.I.A. (introducing the paper): Insurance companies need capital to provide a cushion for unexpected increases in liabilities, unexpected decreases in asset values, inadequate rates, problems with cash flow timing and catastrophes. Regulatory capital requirements based on risk are common in the banking and securities industries, but only recently has attention been paid to this in the insurance industry.

The United States of America saw the beginning of risk-based capital (RBC) systems for non-life insurers in the early 1990s. At their December 1993 meeting, the National Association of Insurance Commissioners (NAIC) adopted RBC standards for property-casualty insurers, to become effective in 1995, based on the 1994 annual statement. Prior to that date, U.S. minimum capital and surplus requirements for property-casualty insurers varied from a few hundred thousand dollars in one state to millions of dollars in another for a company writing the same lines of business.

The NAIC's two main objectives in adopting RBC standards were: first, to develop a standard of capital adequacy that was uniform among all states, and that was related to the risk inherent in the business of insurance; and, secondly, to provide a regulatory authority to act when capital fell below the designated standard. The NAIC's RBC formula contained provisions for dealing with some, but not all, of the risks to which a property-casualty insurer is subject. The notable exceptions are catastrophes, that is the accumulation of exposures, and asset-liability mismatch.

A company's RBC is not, however, a predictor of failure, as studies have shown. The NAIC itself has warned that RBC was not designed for the specific purpose of predicting future insolvencies. Indeed, the model law for RBC specifically prohibits the public use of $\mathrm{RBC}$ as a ranking or rating tool. Yet, it seems likely that insurers will be compared and ranked by their RBC results. This may cause many insurers to work to improve their RBC scores through acquisitions and mergers, through the redistribution of their mix of business and through investment in higher quality assets.

To European insurers, used to a rather simple solvency margin formula, the NAIC RBC formula looks complex. However, some simplification has recently been decided, so that now both reinsurers and primary carriers will be subject to the same formula.

On this side of the Atlantic, the Lloyd's RBC proposals were published in a consultative document in August 1995. There was insufficient time to include a considered response to the Lloyd's proposals in our paper, but we were, nevertheless, able to give a few comments. The move towards the development of a new system in Lloyd's originated in Sir David Walker's report on the L.MX spiral, and is intended to reflect the principle that different classes of business should be supported by varying amounts of capital, depending on the risk to which they put the Central Fund.

$\mathrm{RBC}$ systems are designed to remove the anomaly that, for example, insurers underwriting private motor insurance have to put up the same amount of capital in relation to premium income as insurers underwriting oil rigs. The scheme proposed by the Lloyd's RBC working party is relatively complex, and is based on ratios for individual funds at Lloyd's for each of 143 risk codes, which are then used to generate a weighted average for the underwriting of each Name. The ratios range from $10 \%$ for temporary life or physical injury up to almost $400 \%$ for Lloyd's Names Estate Protection Plan. This basic ratio is then adjusted to allow for portfolio diversification by business class and by managing agent. It is also proposed to allow credits for syndicate reinsurance and for business competence of the managing agents concerned. Because of the complexity, it has been suggested that a computer program will be made available to members' agents to calculate the ratios for their Names' funds at Lloyds.

There has been opposition to the proposals, largely concentrating on what somebody described as 'their mind-boggling complexity'. Most of the publicised responses have been along the lines of "It is too complex, it is very subjective, and there should be a simpler way of doing it".

One of the more valid criticisms is that the historical patterns may not give an accurate indication of future volatility. Indeed, for many of the most volatile classes it is exposures that are significant 
rather than the historical pattern of losses. Even for the worst historical years, however, portfolios that were well-diversified have shown less volatility than those with limited diversification.

Unfortunately, the Lloyd's working party did not explicitly list the size of the business class diversification credit in the consultative document, and this makes it difficult to give informed comment. Also, the weights of the risk codes before the credits for outwards reinsurance appear to have been based on the stability of the results after reinsurance, whereas they should reflect the volatility of the account as if it were written without reinsurance.

There are also some side effects of the Lloyd's proposal, such as the necessity for rigid adhesion to business plans. The RBC rules will be used to indicate the required funds at Lloyd's for all corporate vehicles for the 1996 account. They will be introduced, generally, for the 1997 year of account.

In introducing RBC, Lloyd's will be ahead of the rest of Europe. It is well known that there is a review under way within the Europe Union on the future shape of the solvency margin requirement. In this country, the ABI and the DTI have their internal working parties on the subject. What comes out of the discussions that will take place in the next year will determine the shape of the industry's requirements well into the 21 st century.

The paper also touches on the subject of RBC for insurers' internal use. If solvency is to be ensured, then the bottom line is that adequate premiums must be received. The discipline of allocating capital down to lines of business is one way of attempting to introduce processes and accountability to achieve this. This is an area in which actuaries have much to contribute, and, indeed, are increasingly becoming involved. However, the whole issue of capital allocation is controversial. Whilst the concept of dividing up capital may be against financial economic principles, actuaries cannot afford to be left sitting on the sidelines. They should have a strong role to play in making the achievement of sound financial management, through disciplined pricing, a practical reality.

Mr J. A. Lowe, F.I.A. (opening the discussion): The whole basis of insurance relies on the diversification of risk. The risk to an individual, say, of his or her house burning down is generally of quite considerable financial consequence. To an insurer, however, who may pool hundreds of thousands of such risks, the financial consequences of any insured individual making an ordinary claim are negligible, because the insurer has diversified away what one would call the statistical risk of adverse claims experience.

The only insurance risks, on the whole, that one can quantify meaningfully are precisely those where there are thousands of risks, and hence a credible body of data to analyse. With only a handful of observations, quantification of means and variances becomes meaningless. This gives a Catch-22 situation, where the only risks, on the whole, that you can objectively, reliably, quantify, tend to be those which, by virtue of there being thousands of them, are not particularly risky to an insurer by virtue of diversification.

That is not to say that insurance is not risky or that no insurance company will ever become insolvent. However, the significant risks do not come from anything that can be measured by compounding a frequency and severity distribution or by looking at a run-off triangle. The risks come from more humdrum sources: having an underwriter who tacks on a clause that exposes the company to some new, unanticipated risk, for example, or, perhaps, having those in management who misread what their competitors are doing, or who fail to anticipate the impact of new legislation. All these risks stem from mismanagement rather than from some extreme point of a statistical distribution. None of these risks can be captured by looking at a run-off triangle or by applying multipliers to a balance sheet. This is the second Catch-22, that, if the significant risks of an insurer could be quantified, then they would not be risks. They are risks precisely because they are not capable of meaningful quantification. In the language of the paper, these risks correspond to the specification error described in $\mathbf{I 2 . 3 . 4}$.

Measures of reserve variability and other simple statistical measures are not the 'be all and end all' of assessing risk, and we should not lose sight of the fact that, generally, the risk quantification we can do is only partial and, very often, represents only a small minority of the risks that an insurer 


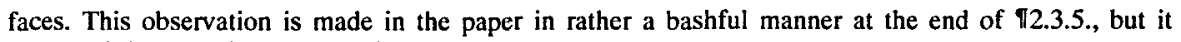
is one of the most important points of the paper.

Turning to the use of RBC to measure performance, which is discussed in Section 5,1 have misgivings about using any allocation of capital to make decisions on the performance of, say, one class of business relative to another, although, as Dr Hooker said, this is certainly a controversial area. However, I do approve of using some sort of risk-adjusted measure in theory, if possible. In practice, actuaries, or anyone else, can measure risk sufficiently well to provide a reliable base from which to make decisions on performance. Also, I agree with trying to quantify financial strength for solvency purposes in some objective way. It is the quantification for the purpose of measuring performance that I am uneasy about. When considering measures of performance, one needs to consider what is risky to the party on whose behalf you are measuring that performance - that is the shareholders. From this perspective, even more of the risk that one could attempt to quantify is diversifiable, and the significant risks, the mismanagement risks, become even more unquantifiable, because they expand to include the risk relative to one's competitors.

I illustrate this with a simple example. Typically, one might try to measure risk for a class of business as a percentage of premium, say $150 \%, 50 \%$ or $30 \%$. How much confidence can we really have that $x \%$ is a true measure of all the risks of a class of business? We are referring to an estimate of the second moment of something for which, realistically, two actuaries are only going to agree the first moment - that is how much money the business is making - to within, say, plus or minus $5 \%$ of premium. It is, therefore, unlikely that all the risks of a class of business can be quantified as a percentage of premium with a confidence that $x \%$ is accurate to within less than, say, $50 \%$ of premium.

One concern is that those outside the profession may take some $R B C$ percentages, calculated by an actuary for solvency purposes, as the 'gospel truth', and may turn down projects that can make a long-term average profit of, say, $12 \%$ of premium in favour of those that make $8 \%$ of premium, because the first class has an RBC percentage of $120 \%$ compared to the second class's RBC percentage of $70 \%$, which gives the second class a higher 'return on capital' in some sense. In fact, the RBC percentage calculations are so imprecise that the percentages, and hence the implication for profitability, could easily be the other way round.

The paper touches on insurance supervision in Section 6. The authors describe various possible approaches, of which statutory professional involvement is the most fruitful area to consider. Many people express concern about how complex general insurance is, and how much harder it is to make estimates of a general insurance company's financial position than, say, a life fund or a pension fund. Yet, the well-established and respected system of regulation used in both of these industries in the United Kingdom does not rely on a simple formula applied to a handful of balance sheet items to give the regulators comfort. They rely, centrally, on the statutory role of the actuary, acting within guidelines agreed between the profession and the regulators. I am sure that there is a moral here for general insurance.

There are also lessons to be learnt from the banking industry, which has recently seen a number of spectacular failures, partly because of the inability of a rigid formula to pinpoint more subtle mismanagement risks. The Committee of International Banking Regulators is moving away from RBC to a new regime of more flexible regulation from 1998. This new regime is likely to place more emphasis on the company's own assessment of risk rather than an externally prescribed formula. As an alternative to formula-based risk measures, I understand that some bankers are moving towards stress testing. This approach looks at specific, but possible worst, cases, and uses these as a benchmark of financial viability as being more representative of risk than, say, some multiple of standard deviations. I suspect that this stress testing approach may have more to offer the regulator than a formula-based approach.

Given my reservations about our inability to quantify risk, and the limitations of $R B C$ in the banking environment, I do not advocate an RBC system as a basis for insurance supervision. Rather, the best way forward for the general insurance industry is a statutory role for the actuary in general insurance, not just for reserving, and not just at a given point in time, but rather on a dynamic basis, looking at solvency threats from a variety of sources, perhaps along the lines of stress testing, and 
possibly within a similar framework to that in the life and pensions industry, that appears to work well.

Mr P. W. Wright, F.I.A.: I was disturbed to see that the financing structure of holding companies was included in $\uparrow 2.4 .24$, where, presumably, it is seen as a candidate for inclusion in a RBC formula, rather than in 12.4 .25 , as part of the soft issues that RBC formulae "would not readily be able to deal with". The extent of borrowing at holding company level may be a reasonable factor for the regulators to take into consideration when assessing the fitness of a controller of an insurance subsidiary, but should not feature in any formal assessment of capital adequacy. In this connection, the proposed European Union directive on the supervision of insurers in insurance groups is objectionable in the way it attempts to assess the solvency of a holding company and, if enacted in anything like its current form, may cause significant problems for U.K. groups.

The authors state, in 12.4 .8 , that "there is no investment that can be used precisely to match assets with insurance liabilities", and if anything, this is an understatement. However, throughout the paper there are numerous references to mismatching risk as if this is separate from, and additional to, movements in the market value of investments. There appears to be some double counting here. The reference, in $\Uparrow 3.4 .4$, about the U.S. formula, should be reviewed, since the U.S. RBC formula does allow adequately for fluctuations in market value of equity investments. Fluctuations in the market value of bonds is presumably ignored, because of the use of amortised book values for these investments.

The references to currency mismatch and investment diversification are confusing. In some places the risks associated with currency mismatch are emphasised, but in others the benefits associated with investment diversification are highlighted. The paper seems to come down, in $\$ 4.3 .9$, against currency mismatch, and suggests that this should be a factor in any RBC formula. I am not sure that this should be accepted, particularly for assets backing very long tail liabilities.

I thought that the conclusion, in $\mathbb{4} 4.4 .7$, that the absolute level of RBC was of lesser importance than the relative levels for individual companies, is rather surprising. The absolute level of required capital is of over-riding importance, not only for the company being assessed directly, but also to ensure that the valuation rules for dependent general insurance companies include a realistic deduction for solvency requirements, and do not encourage artificial group structures to be adopted to inflate reported DTI solvency.

If the assets referred to in $\$ 4.2 .6$ could be realised at short notice for value, then should we not question their former state of inadmissibility rather than call this "window dressing'? In $\$ 4.3 .8$ it should be made clear that any catastrophe risk charge should be net of any claims equalisation reserves. I was surprised to see the reference to PRE in 97.1 .11 , given the statement, in 11.1 .4 , that "In the remainder of this paper we consider only a pure non-life insurer". In 14.4 .1 it would, perhaps, be more correct to say that some statistical distribution can be used for asset risk. Whether the distribution selected suffers from parameter uncertainty or specification error, referred to in $\$ 2.3 .4$, is a debatable point.

Concerning dynamic solvency testing (DST) in the U.K., it is proposed to introduce DST on a nonmandatory basis for long-term insurance business. Here the requirements for DST will be superimposed on all the existing valuation requirements, including the cover for both the resilience reserve and the statutory solvency margin. This seems a sensible approach, and I would expect a similar one to be adopted for general insurance. The impression, however, given by Section 6.3, is that DST would be required as an alternative to a realistic solvency margin.

Mr J. P. Ryan, F.I.A.: It is important to realise that RBC is, essentially, a regulatory tool, a tool for investors and, perhaps, for rating agencies as well. It provides additional information that assists third parties to enable them to assess the ability of companies to continue to pay claims and similar types of issues. The availability of this kind of information to third parties is something that is not easily provided by introducing a statutory role for actuaries. It is in this context that RBC is particularly valuable, and, therefore, should be encouraged.

The authors state that RBC might not, necessarily, be a very good predictor in isolation, but this 
does not detract from its value, in that it provides useful supplementary information that would not otherwise be available.

Internally, asset liability management (or dynamic solvency testing or other variations) is a more practical company tool than RBC. Here you need to introduce concepts such as efficient frontiers, including liabilities and utility curves, and also to consider issues such as market driven risk rates of return in order to understand and utilise the concepts involved.

In I2.3.4 the authors cover the issues of process risk, parameter uncertainty and what they call specification error. These are clearly three very important issues. The paper by Dr A. J. G. Cairns, 'Uncertainty in the modelling processs' (Transactions of the 25th International Congress of Actuaries, I, Brussels, 1995), provides a very good intellectual framework for evaluating these topics.

Another issue is whether one should operate RBC on a purely statistical basis, or should also include subjective elements. As applied in this country to banks, there are considerable subjective elements in terms of management credits that arise out of visits by the supervisory authorities to the individual banks. That involves the authorities taking a view on the adequacy and efficiency of management systems, and they use this information to supplement the RBC. For this reason, it is difficult to publish the RBC, and the numbers are not readily available, but it is an interesting addition that could be used to supplement RBC in the insurance industry.

In 12.4 .5 the authors stress the importance of the underwriting cycle. An interesting question is whether or not we can model it mathematically, and so reduce the capital requirements. In some areas, such as motor insurance, we can produce models, but, in my experience, these do not necessarily improve forecasts for capital purposes over the time horizons with which we have to operate.

There has been some comment that premium income is an inadequate measure. If we could get exposure information, it would be preferable to using premium volume in isolation. The Lloyd's formula requires that the actual allowance be varied according to market conditions, to allow for this fact, in terms of the relative profitability of differing premium levels. Claims might be thought of as a possible alternative, but this would leave the formula open to some form of manipulation.

In I4.3.4 the authors say that allowance should be made for outwards reinsurance, but they do not say how. The Lloyd's basis was to take reinsurance on an average basis, so implicitly assuming that reinsurance is averagely purchased across the market. This is recognised as an area where further work needs to be done, and the present situation is not perfect. Badly purchased reinsurance programmes might well have a negative value. It is an extremely difficult subject. Even proportional reinsurance is subject to disputes, and, therefore, full credit should not be given for it; and nonproportional reinsurance is much more complex.

I agree with the authors that relativities are more important than absolute levels, although $\mathrm{Mr}$ Wright disagreed. However, in Section 4.4, they suggest that one should spend time obtaining the various distributions. In Lloyd's, we found that the distributions were not terribly sensitive to the relativities, and, therefore, I would disagree with the authors to some extent. In particular, for the vast majority of companies, the central limit theorem can be used to calculate the relativities. In the context of Lloyd's or the London Market this may not be appropriate; but, provided the distributions are broadly similar, the results are not sensitive to the distributions.

Capital allocation is much easier in an asset liability or dynamic solvency testing environment than in a RBC environment. The means of allocating investment income is a complex topic. The authors suggest that this should be done at a risk-free rate. I disagree. If you apply a full asset-liability analysis and look at the marginal effect, you are likely to come up with a target investment rate of return that is determined by the investment strategy, rather than a risk-free rate.

Mr D. H. Craighead, F.I.A.: My comments concern the conclusions to be drawn along the lines of Section 6, dealing with insurance supervision, expanding the argument advanced by the opener.

While controls based on a RBC type calculation, as are being adopted in the U.S.A. and discussed within Lloyd's, will undoubtedly be a useful tool in terms of statutory supervision, they cannot be the complete answer. Such controls would not have prevented the debacle that occurred among Lloyd's syndicates and reinsurance companies as a result of the totally unexpected aggregation of catastrophes in the years 1988 to 1992 . What is missing, so far, in the formulae being adopted, is any way of 
monitoring the exposure to aggregations of risk, as stated in $\$ 3.4 .23$. Nor is that likely to prove the sole weakness in the formula-type approach. There are other factors that can readily play an important, though not, perhaps, so uniquely important, part in the solvency of an office as did the catastrophes. Currency mismatch is one; the misreading of the precise effects of reinsurance contracts is another. Latent diseases have been mentioned in terms of asbestosis, but others, of perhaps less serious impact, may still be sufficient to tip the balance.

The concept of risk presents unique difficulties of formulation - it is more a matter of judgement than of precise measurement. These shortcomings of the formula approach apply particularly in regard to reinsurance underwriting, but they may also apply to some extent to direct-writing personal lines offices, as was shown by problems arising from mortgage indemnity coverings and subsidence claims.

The answer, ultimately, will be for sufficiently trained and experienced personnel, probably all actuaries, to be required to provide a role parallel to that of the Appointed Actuary in life insurance. For such an actuary, guidelines could be provided similar to those of GN12, but suitably expanded in consultation with the DTI. Ultimately, the responsibility would rest on judgement to an even greater extent than it does in life insurance.

Do we, as a profession, have the personnel suitable for such tasks? The late Sydney Benjamin stated his opinion, several years ago, that suitable personnel could then be provided, and in sufficient numbers. I expressed reservations then, but I think that we are now beginning to be ready for such a role. One has only to know that the insolvency of at least one office was caused by horizontal exhaustion in reinsurance protection from four catastrophically large marine claims in 1989, when there was only provision for reinsurance for the original plus two reinstatements in most treaties, rather than from vertical exhaustion, to appreciate the difficulties of such a responsibility.

Such a role would involve the Appointed Actuary probing into every aspect of an office's operations, from underwriting to investment. It would involve a new, and greatly enhanced, degree of responsibility for that person, but such a step would bring with it the only possibility of plugging those gaps that RBC formulae cannot cover.

Mr G. G. Wells, F.I.A.: It is important to have a level playing field for solvency standards. The method needs to be relatively simple, so that it is understood by all parties, including underwriters, but also comprehensive enough to cover all the issues. The Lloyd's RBC proposal has several disadvantages: it creates playing fields with European and U.S. competitors that are not level; it is complex; and it does not have $100 \%$ support of the underwriters.

I now consider two examples of $\mathrm{RBC}$ and risk management:

(1) In a bank, a solvency margin of between $1 \%$ and $4 \%$ of mortgages or loans is required. The risk could be transferred to an insurer for a premium lower than the solvency requirement, and the insurer's own solvency margin would be a mere fraction of the original level. Solvency would be decimated. Up to 1988 , the losses on the mortgage guarantee business were minimal solvency was not an issue - and any RBC calculation would have justified the lower solvency margin. The fact that the risk had radically changed was not an issue with the insurers, and the resulting financial losses caused to the major composites was the end product. If the true risk had been assessed at the proper level (that is, similar to the assessment of the banks), then the premiums would have been considerably higher to support the capital, and insurers would have been made aware of their exposure.

(2) This relates to the catastrophe exposures that are being run by many insurers. Based on a rate on line of 25 for a monoline risk, with one reinstatement, the capital required is $600 \%$ of the pure premium to guarantee solvency. Attaching similar risks does not help diversify the problem. Writing similar risks with different exposures has the mathematical benefit of spreading the risk, and people believe in the mathematics. We cannot possibly have two or three major catastrophes in different parts of the world in the same year, can we? Sadly, experience indicates otherwise. We need to consider, not just the type of business, but the risks within the line. You need to ask, "How many major events are there to be before a reinsurer has difficulties?" I suggest that, for some, the answer may be as low as two or three. 
Both of these examples indicate the need to have exposure measures in deriving the necessary capital to support the risks. The RBC approach only includes exposures in a superficial way, and, unless there are historic losses, will underestimate the potential risk.

The allocation of capital is fundamental to pricing. Unfortunately, in traditional pricing in the market, the impact of capital is mostly ignored, or, at best, an inadequate proxy is used. The use of stochastic profit testing techniques will illustrate the risks being run, and indicate the reasonable capital to support the underwriting. At the whole business level, the solvency assessment is, perhaps, best served by a stochastic model office. Such models are forward looking, unlike RBC, and automatically give a range of estimates of future cash flows, which gives managers a substantially better view of the risks that they are running compared with a formula-based approach.

Mr A. D. Smith: Several difficulties in the use of RBC for performance measurement are pointed out in 95.2 .8 , but the list is far from exhaustive. The opener has filled us in on a few more, and here is another example. Suppose that shareholder required profits by line can be calculated as a rate applied to RBC, as suggested in 15.4.3. If a large company is split into several legally independent operating units, the aggregate RBC requirement (as calculated by the formulae described) usually increases, implying that shareholders should require a greater profit from the sum of the parts than from the original whole. This does not appear to make sense - I think that the sums ought to produce the same figures, and if they do not, there may be some fundamental inconsistency undermining the whole approach. In I5.3.5 it is suggested that these sums could go either way. I disagree; with the NAIC method and, possibly, with the Lloyd's formula, the capital requirement for the whole cannot be more than the aggregate of the requirements for each part.

Several methods have already been developed to adjust for risk, both in pricing and in performance measurement. In the traditional actuarial literature, premium calculation principles are proposed which adjust best estimate distributions using various measures of risk. This is mirrored in option pricing theory by the analogous construction of risk-neutral measures. Others have suggested that risk should be taken into account by adjusting discount rates, with the Capital Asset Pricing Model being the most widespread recipe for doing this. We are considering here yet another technique, where, in effect, premiums are loaded up for the cost of risk capital in excess of the earned rate.

All of these methods make some sense, and, if carried out carefully, can give meaningful answers. Economically and mathematically they are equivalent. The assumptions of one method can be transformed into an equivalent set of assumptions for applying a different method. All the methods, when carried out consistently, will give the same answers and will result in the same decisions. I note that, when examining risk from a shareholder perspective, we are not interested in the marginal contribution to a particular company risk, as outlined in $\$ 5.3 .8$, but rather in the marginal contribution to the portfolio risk of all the shareholders' combined investments. This rather changes the nature of the required calculations, and the $\mathrm{RBC}$ then seems less intuitive.

In view of this, I find it hard to accept that $R B C$ gives a totally new insight into required returns. Rather, it gives us another way of computing answers that we had already calculated by a different route. It is futile to contrast the various methods from an economic perspective; rather, computational convenience is the only discriminating feature. Of all the competing approaches for calculating shareholder required returns, RBC is the most clumsy and involves the largest number of arcane intermediate steps. These steps include: anticipation of the gross business and reinsurance protections before any of the business has been written; implementation of the chosen $\mathrm{RBC}$ formula for the whole; recalculation, omitting each business line in turn, to determine marginal capital usage; adjustments to allocate the surplus or deficiency relative to total capital; further adjustments for marketing top-up; further possible adjustments to avoid credits for negative marginal capital usage; further adjustments for prior years still developing; determination of an appropriate overall required rate of return; risk adjustments to this return, possibly by line of business; adjustment of the required profits to reconcile in total with the return you first thought of; further adjustments to allow for risks inadequately covered in the RBC formula or included in the formula to too great an extent; adjustments for risks which are diversifiable by shareholders and continued reappraisal of profit targets for each line whenever the volume or nature of business for other lines does not hit the 
anticipated target. It may be that such complexity is necessary for statutory supervision, but it seems rather excessive for general management when simpler solutions are already available.

Mr D. I. Tomlinson, F.I.A.: An argument that I have heard can be summarised as follows: companies are run by businessmen who aim to make profits; they know more about insurance than any actuary; so they do not need any capital at all. I have heard that argument, in a modified way, from people who like to run their companies with minimum capital, and in a less modified form from companies that have got into trouble, have used up their capital, but think that they should be allowed to trade because, ultimately, everything is going to be profitable and they will recover.

If that is what we do not want, what do we want? We want enough money in the company so that policyholders still get paid when things go wrong. Some things cannot be dealt with practically by means of RBC. These include fraud, the failure to buy the right reinsurance, and the failure to get PMLs right. The capital required to protect against these contingencies is so large that it is impractical.

Listening to the discussion, I am still left in some doubt as to what we mean by RBC. When I talk about RBC, I do not mean the system that the Americans have introduced; that seems unduly rigid. However, I do think that there is an advantage to look at the capital required when things go wrong, and that I call RBC. Thus, I do not necessarily agree with the comments of the opener that it is not going to be very helpful to us. I would go some of the way towards dynamic solvency testing possibly all of the way. However, if you are going to produce regulations, there may be problems.

The required minimum margin of solvency defined by the E.U. is under discussion, as it has to be reviewed by 1997. Currently, I doubt if anyone knows what will emerge from the review: possibly a move to a RBC approach will result; possibly something different; or possibly we will stick with what we have at the moment.

One of the things that concerns me is the adequacy of premium levels and reserves. If a formula requires, say, $x \%$ of premiums as a margin, then the company that is undercharging gets away cheaply just when it needs more capital. This applies also to reserves. In long tail business, you can quite reasonably have very different levels of outstanding claims that can be described as 'best estimate'. It is not just that provisions might be low and there is a lower risk-based capital charge, but actually there is the shortfall between what you have and what someone else has. This is an area where actuaries can make a contribution. In particular, actuaries reporting on that kind of business might help if they include assessments of potential downside, and, certainly, if they write reports that will be seen by the supervisor.

The comments in the paper on stochastic variability, uncertainty, parameters and model specification error are very important. I disbelieve people who say "here is a black box, and the result is a probability of ruin of $3 \%$ ", because there are many hidden assumptions in this.

If I were designing a new system, I would use a RBC approach, but I would let the percentages be set almost on an individual company basis, depending on what they are doing and how strong their reserves are.

Professor H. Bühlmann: Dynamic stress testing is the right method for assessing capital adequacy, and the book Practical Risk Theory for Actuaries, by Daykin, Pentikäinen and Pesonen shows you this method.

What then about the formula? Any formula should be tested, whether it gives you more or less the same answer as if you do dynamic stress testing, because a formula is no more than a rule of thumb. If you have a formula that works, it would simplify calculations very much, and you can explain it to other people. The role of the formula, in this context, should be as a simplification of the correct method, which is dynamic stress testing.

In looking for such a formula, it is obvious that capital plays a role, but another element that has not appeared sufficiently in this discussion is profitability. There is a trade off between capital and profitability. If you run an insurance operation with a premium loading of zero, you need infinite capital. If you run an insurance operation with no capital, you almost need an infinite premium; so there is a balance point between these two extremes. If there is one criticism of the American formula, 
which has a lot of merit, it is probably that it stresses capital and forgets about profitability. A good formula, that tries to achieve what dynamic stress testing would do, would play on these two elements: capital on one side and profitability on the other.

Mr C. J. W. Czapiewski, F.I.A.: In considering RBC properly, we need to understand the fundamentals of insurance. Concerning the practical use of RBC in general insurance, either for internal management purposes or for regulatory control purposes, many U.K. insurers currently use such techniques. Lloyd's is introducing them, and probably the DTI is considering this type of approach for external regulatory purposes.

Risk is dynamic and not static. The use of past data can be permitted as a guide to the future, but we must consider the changes in policy terms and conditions, in pricing levels, market conditions, business strategy, and all the other factors that combine to affect the claims emerging from a book of business. Actuaries are quite used to looking to the past to help with predicting the future, but with $\mathrm{RBC}$ we have a very highly geared position, in that we are dealing with business that is yet to be written, and not dealing with a projection of claims that have occurred.

In addressing the use of $\mathrm{RBC}$, we are interested in the volatility of claims, especially when claims exceed premiums. It is important to consider two situations very separately:

(1) short-term volatility, but with adequate longer-term premium levels; and

(2) longer-term premium adequacy or inadequacy.

If you adopt a method that does not explicitly separate these two items, double counting and confusion are likely to occur.

The following areas can have a significant effect on $\mathrm{RBC}$ requirements:

(1) Too much importance is given to the class of business involved. By introducing a spread of business into independent areas, far less capital is required. For example, if you obtain a geographical spread in about 10 separate areas, the RBC requirement might only be $30 \%$ of that required for one geographical area.

(2) The level of the insurance or reinsurance written is very important. If working layer business is written, where losses are expected every year, and where most variation is caused by pricing levels, then far less capital is needed than for writing the more volatile high layer catastrophe or clash business, where losses are much rarer.

(3) Although the amplitude or variability of losses is important, far more so is the wavelength; that is the amount of time spent in a deficit position. The capital required must be sufficient to protect against this cumulative strain.

(4) The assessment of the effects of reinsurance is hard, even without allowance for bad debts. Proportional reinsurance can be allowed for by assuming a pro rata or similar reduction. Excess of loss and stop loss insurance are far more difficult. Vertical and horizontal aspects of reinsurance must be considered. The only real solution is some sort of simulation approach, although, for simplicity, a less accurate deterministic approach may have to be used in certain circumstances.

RBC is an excellent tool. It can work in theory, and it certainly does work in practice. As in so many areas of insurance, considerable experience is needed to make it work properly, and it is all too easy for poor practitioners to make very serious errors and omissions.

Mr C. Miranthis, F.I.A.: In $\$ 2.4 .23$ the authors mention the significant relationship between growth

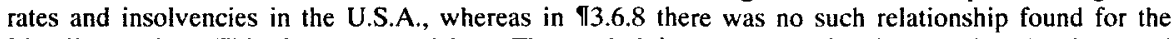
Lloyd's market. This is not surprising. The underlying structure in the London Market, and particularly the subscription nature of the slip system, means that growth or downsizing can be achieved through means which are not available in a non-subscription market; for example, sizing up or down written lines.

The issue here is that any formula should take into account the underlying structure of the market in which it is meant to apply, although, as a matter of practicality, it would be very difficult to have 
two different formulae applying for a domestic market and an international market that co-exist in the U.K.

In \$4.4.10 there are two suggestions which are far from convincing. First is the suggestion that there should be no overall covariance adjustment, and, secondly, that any covariance adjustment should not be applied to the reserving charge. The argument that there should be no overall covariance adjustment is that the overall level of RBC will, of necessity, be politically determined. This, however, ignores the functional form of the adjustment needed, that is, the approximate interrelationship between the various charges which, in the case of uncorrelated charges proportional to the standard deviations, reduces to the square root rule. While the authors rightly mention that the covariance adjustment should vary between companies, because, for example, of different assetliability matching policies, there is no suggestion as to what should replace it, or how it may be individualised to each company's circumstances. Even a crude covariance adjustment, such as the square root rule, is better than nothing.

The second suggestion is that no covariance adjustment should apply for the reserving charge. The authors' main premise on this is that any company, through its processes, will tend to over-reserve or under-reserve in a systematic way. While there may be some truth in this, I believe that the more diversified by class of business the company is, the less the risk to the company's reserves is from adverse deviations.

In reality, a small number of future events, such as a change in legislation, are likely to have a major impact on a company's reserves. It is unlikely that these changes will affect all classes of business in the same way, or, in other words, the more classes of business there are, the less the risk of model mis-specification. The authors' own comments in this area on the importance of model specification are a powerful argument for having some covariance reserving credit.

Mr P. J. Nowell, F.I.A.: I am not convinced that the U.S. system deserves so much criticism. It is easy to criticise an existing system as being over-simplistic or not working in certain situations, or, indeed, not actually predicting failures. The opposite danger is to become over-complex to a degree that nobody can really follow the approach, or that it is so subjective that it does not really have any meaning. If it were possible to have a common approach around the world, it would make matters a lot easier.

The authors discuss some of the shortcomings of the U.S. system, and point out some ways in which an alternative might be better, but what is actually being proposed, and what would actually happen, in practical terms, to an alternative? Therefore, what I should like to see is a development of the ideas in the paper into some sort of realistic model of a typical company or companies. Then we would have something to work on, to be able to see how well the proposed system worked, and to investigate any shortcomings. Then we could begin to converge onto a methodology that really worked.

One approach would be to see whether we can come up with alternatives that are demonstrably better than the U.S. system. In that way, rather than debating fine points about where you draw the line on certain things, we could converge towards a practical solution to the problem of keeping companies solvent, but, at the same time, minimising capital requirements and maximising profitability.

Mr J. M. Charles, F.I.A.: I should like to draw attention to the possible economic implications of introducing RBC as a regulatory tool. The idea of introducing capital requirements that are related to levels of risk is appealing from an actuarial viewpoint. Taking a wider economic perspective, however, it creates a market distortion, in the sense that it may affect management behaviour in encouraging business decisions related to capital requirements, as against profitability, in the context of an individual company's knowledge and skills within the insurance market.

Dynamic solvency testing provides a powerful framework for developing a supervisory system that is flexible. However, I think that we should consider carefully our prospective role within such a framework. 
Mr A. J. Newman, F.I.A.: In Section 4.2 the authors discuss desirable features of RBC, and mention coherent conceptual frameworks, for example, the probability of ruin or the expected policyholder deficit. A cross between them - the probability that the policyholder deficit exceeds a certain amount - could be justified on the grounds that, for example, the Policyholders Protection Board has a limit as to the maximum policyholder deficit it can fund, and, similarly, the Lloyd's Central Fund has selfimposed limits on the levies that it will take from the future market.

In Section 4.3, $R B C$ Components, reinsurance security falls under credit risk, reinsurance recoverables and agents' balances, IBNR recoveries and outstanding payments. With cases going through the courts at the moment, it is noticeable that the reliance on reinsurance is not necessarily a good thing. However, while on the one hand you would like to increase the RBC requirement for a company that relies heavily on reinsurance, on the other hand you would not like to increase it too much, because you might discourage reinsurance. The behavioural impact is going to be difficult to assess, but it needs to be taken into account.

Regarding the calculation of risk charges for diversification and management competence, there seems to be almost universal agreement that diversification by class of business is good. The paper mentions, in $\$ 2.4 .25$ and those following, that there is no objective measure of management competence. Against both of these ideas, 1 would point out that many of the problems at Lloyd's stem from underwriters having strayed into classes of business that they did not understand, and that diversification should not necessarily, therefore, be seen as a good thing.

Mr R. Manjrekar, F.I.A.: We need to keep the RBC requirements for solvency separate from any internal capital allocation requirements for the business management. For the latter, we are trying to quantify a best estimate of capital allocation, together with the risks inherent in that allocation. The purpose of such an exercise would be to evaluate different business strategies in order to select the one which best meets the requirements of all the stakeholders in the company. On the other hand, the RBC, for solvency, would focus mainly on the policyholders' interests.

Paragraph 4.2.11 mentions the need to integrate RBC with the asset and liability valuation regime, in particular with reference to the issues of discounted reserves and equalisation reserves. These concepts are difficult enough on their own, and become much more complex when considered together. This complexity should not be underestimated, and we need to carry out further research in these areas.

Mr R. C. Tulloch, F.I.A.: As a general insurance examiner I thoroughly recommend this paper to any student, because it adequately spells out the various risks involved in general insurance, a problem that most students find very difficult to grasp. Most seem to consider claims as being the only risk. The paper highlights that claims are not the main problem for a general insurance company.

Mr. A. N. Hitchcox, F.I.A. (closing the discussion): The need for capital in an insurance company arises, partly to afford protection to policyholders against the inherent uncertainties in the values of assets and liabilities, and partly because we collect premiums on an annual basis to fund losses that may happen only infrequently - for example, a hurricane or an earthquake once every 50 years. Insurance companies spend much time measuring the capital we actually have, but we are still not well versed in measuring how much capital we ought to have relative to the risks we are running.

$\mathrm{RBC}$ is an approach that addresses this issue. Actuarial involvement in general insurance is often still weighted rather towards the reserving side, but if we are seen, as a profession, to develop our skills in RBC, we should be able to increase our involvement in the underwriting and risk taking sides of the business.

In Section 3 the authors address the experience of RBC in the U.S.A. I agree with Mr Nowell that this system deserves less criticism than it currently attracts. Even though the formula published by the NAIC might not be perfect, it has already acted as a catalyst to persuade managements to take sensible decisions. In the life insurance industry, companies have divested themselves of assets that doubled up on the risks contained in interest sensitive products. In the property and casualty (that is 
general insurance) industry, companies have been withdrawing from long tail lines of business if they feel that the margins are not available to justify the reserving risk.

Much attention is paid to evaluating any given RBC system according to the numbers of insolvencies that it does, or does not, predict. However, this loses sight of the benefits that a RBC system can bring to the great majority of companies who reasonably expect not to become insolvent. For example, in the U.K. two great sources of financial loss in recent years have been domestic mortgage insurance for the primary market and the LMX spiral in the reinsurance market, as referred to by $\mathrm{Mr}$ Craighead. Both of those losses arose because of exposures of which account was not taken. If company managements had fostered a proper risk-reward measurement culture, arising from the external requirement to relate capital to risk, these losses would have been less likely to occur in the magnitude that they did. The promotion of this sort of culture is one way to deal with the mismanagement risk that concerned the opener and $\mathrm{Mr}$ Tomlinson.

In Section 5 the authors address the reasons for allocating capital. The chief desire is to find an economic basis for the allocation of capital and returns on capital by business unit. Assuming that you can overcome the reservations of the opener, one of the benefits that flow from a RBC approach is that it allows a company to compare and contrast the values of different product lines on a consistent risk-adjusted basis. This enables you to assess the true value of a customer who buys many different products from you, and provides the necessary financial underpinning for a company that wishes to reorganise itself on a customer-focused basis.

On the subject of insurance supervision, there is always concern that increased reporting requirements add a burden to the industry. My own experiences with using $R B C$ as an internal management tool convince me that it is a valuable aid in running a company. So, the regulators should not be reticent about leading the industry to better practices. RBC has done the U.S. insurance industry a lot of good, and insurance companies in Europe can only benefit from its introduction.

We have heard about dynamic solvency testing from several speakers. Indeed, I am aware that several insurance groups in the U.K. have already been making progress beyond the rather static nature of RBC, and have been exploring successfully the uses of stochastic asset/liability modelling in assessing capital requirements and underwriting strategies, using the techniques that were referred to by Mr Ryan. It is techniques such as these that will allow the company to assess the impact of catastrophe exposures and asset-liability mismatches that are not treated under the current NAIC rules. As Mr Smith mentioned, these techniques need to be carried out carefully, but any solutions would need to be subject to meeting a requirement for regulatory capital, and this will act as a constraint on the best economic solution. As described by Professor Bühlmann, these techniques allow you to quantify the balance between profitability and capital for solvency purposes.

When managing a general insurance company, we are running a whole variety of risks, both from assets and from liabilities, and, equally importantly, from their mutual interdependencies and correlations. It is a dereliction of duty to manage our companies without trying to quantify these risks.

Insurance companies sell the service of risk management to their customers, but, as an industry, we are still not very sophisticated when applying risk management to ourselves. RBC is a very important step on the way forward, tackling the problem of how to allow for variability and risk at the total company level in planning and strategy.

The President (Mr C. D. Daykin, C.B., F.I.A.): It remains for me to express my thanks, and the thanks of all of us, to the authors for their paper. The working party grew out of the traditions of our General Insurance Study Group, as many of you here will be fully aware, which sets up a number of working parties each year to report back to the subsequent convention the next year. Having been Chairman of the Solvency Working Party of the GISG, which, in some senses, was a predecessor of this particular working party, I am very conscious of the amount of work involved, and the challenges presented by doing research through this particular methodology.

I am grateful to Professor Bühlmann for the 'plug' for the book Practical Risk Theory for Actuaries. One might see that as an outcome from the work of the Solvency Working Party, which was operating for about five years in the 1980s, and co-ordinated its activities very closely with parallel research taking place in Finland. 
The subject of RBC and solvency margins has become highly topical again, particularly with the development of RBC in the U.S.A. There has not been any specific mention of its predecessor, the Minimum Continuing Capital and Surplus Requirements in Canada. These have been driven by the needs of regulators to find a suitable peg on which to hang intervention into a company's affairs before the assets become inadequate to meet the liabilities. In the case of the Canadian requirement, it was initially based on the need of the industry to find an adequate standard of capitalisation before allowing companies to be eligible to participate as potential claimants from the compensation fund, COMPCORP.

The E.U. solvency margins were originally seen in very much the same light. They were derived from a considerable amount of work of a risk-theoretical nature in the 1950s, with the aim of finding a suitable hierarchy of intervention mechanisms which would be suitable for the development of a single market of insurance within the E.U. Crude though they are, they have served that purpose, and have performed the function so much needed by a regulator, of allowing certain levels at which intervention can take place.

The original work by Professor Campagne of the Dutch Verzekeringskamer (insurance supervisory authority) and others from the O.E.C.D., which led to the proposal which went to the E.U., was based on the concept that reserves would include significant margins, because they would be undiscounted, and they would, therefore, be prudent relative to the expected outstanding claims. Furthermore, they anticipated that assets would be valued at book value and would contain hidden margins. They, therefore, focused almost exclusively on underwriting risk. The original recommendation from the O.E.C.D. insurance committee was for a solvency margin of $25 \%$ of premiums. It took 16 years of intensive negotiation within the E.C. to arrive at the more sophisticated and less onerous formula of $16 \%$ or $18 \%$ of premiums. It was held by the regulators that to impose $25 \%$ would be much too difficult, because too many companies would appear to be insolvent.

We can see RBC as having a regulatory purpose, but it also has other uses, as shown in the paper, and, perhaps, those are the ones on which one should concentrate, to balance the previous emphasis on solvency regulation. Equity between Names at Lloyd's has been a particular reason for developing RBC there. Profit testing and setting appropriate premium rates is another important area, as is capital allocation for internal management of the business. All these are management needs rather than regulatory concerns.

On the regulatory side, it has been mentioned that the E.U. is reviewing the solvency margin regime. This is going to take place over the next two years. There is no doubt at all that the supervisors' working party reviewing this will be looking at the possibility of $\mathbf{R B C}$. In my view there are two things that they will be looking for, relative to our existing system. One is more sophistication on the asset side in relation to the evaluation of risk, and the second is a greater distinction between the capital requirements for different types of business.

There is little chance that the 15 member countries of the E.U. could agree on a formula anything as complicated as that adopted in North America, although it was managed there with 51 jurisdictions, through a process that is not currently available within the E.U.

The DTI, acting in the U.K., could introduce such a system unilaterally, on the basis that the U.K. market needs it more than others, because it is more variable in the type of business that it writes. One suggestion was that it could be made a condition of showing that you are sound and prudently managing your company under the recent Insurance Companies Act. I am not sure that it is likely to come in by that route.

The Groupe Consultatif is active in this area. In 1986 it produced a recommendation from its Solvency Margin Working Party that you could not produce a suitable formula, but that there should be actuarial reporting. It is my guess that the Groupe Consultatif will push a similar line on this occasion. I think that what they will be looking for, in modern terminology, is a Financial Condition Report supported by dynamic financial analysis, dynamic capital adequacy testing or dynamic stress testing, whatever you like to call it. There is a good chance that some of the supervisory authorities, at least, might be attracted to this as a solution rather than the formula approach.

I congratulate the authors on a topical and most interesting paper. 
Dr N. D. Hooker, F.I.A. (replying): The President mentioned the E.U. solvency margin formula, and I was surprised that, in the discussion, there was little reference to its shortcomings compared with the U.S. or the Lloyd's proposed RBC systems.

I was interested to hear about the possible greater concentration on asset risk in the European environment. It has been estimated that, in the U.S.A., the increase in interest rates between September 1993 and September 1994 produced more than a $\$ 20$ billion reduction in the value of property casualty insurer bond portfolios, which is more than the losses attributable to Hurricane Andrew. That emphasises the point that it is not just losses that we have to consider.

The opener mentioned that he would like to see a statutory actuarial role, and many of us agree. However, a number of companies are actually seeing the benefit of involving actuaries internally without there being a statutory requirement to do so. He also mentioned dynamic solvency testing, as did a number of other speakers, and that needs to be developed further.

Mr Ryan mentioned the subjective elements of RBC formulae, and $\mathrm{Mr}$ Tomlinson mentioned having formulae which varied according to the individual company concerned. I can see arguments on both sides. It depends on whether or not you are primarily trying to persuade companies to improve their business processes.

Mr Craighead mentioned the important point of monitoring exposure to aggregations. It is difficult to see how that could be encapsulated in a formula. That is where the statutory involvement of an actuary would be of some benefit.

Mr Wells pointed out the need to consider a level playing field, and, particularly, in terms of the risks that appear in the banking industry or could equally appear in the insurance industry. That is also very important.

Mr Smith mentioned that a number of the methods that are available for pricing are all equivalent if carried out correctly. The advantage in looking at it from the capital allocation viewpoint, using $\mathrm{RBC}$ techniques, is in being able to report to management without calling upon the black box concept. We see that as one of the major benefits.

Mr Czapiewski talked about the need to consider more than just the notional class of business, and to consider spread, particularly geographical spread, as a way of diversifying the portfolio. Also, it was important to consider what layer you are writing at. I tend to agree.

\section{WRITTEN CONTRIBUTIONS}

Mr B. R. P Joseph, F.I.A.: The authors have, in this paper, consolidated a number of papers on riskbased capital, and have attempted to address a broad framework for such a system in the U.K. and, indeed, in the E.U. They have also extended the discussion to look at the benefits of RBC to a company's shareholders and management. I would like to address two themes within my comments:

- the components of the RBC formulae proposed in Section 4.3 and its calculation; and

- some of the issues entwining capital allocation and RBC.

In Section 4.3 the authors establish a number of components which should be included within any E.U./U.K. RBC formulae. They also recognise throughout this section the non-independence of assets, underwriting cycles and classes of business. I caution that the covariance parameters mentioned by the authors are likely to be difficult to estimate in practice. We are, in most circumstances, unable to define precisely any of the underlying statistical distributions. Further, the inclusion of many of these covariance parameters, whilst intuitively correct, may render the RBC formulae valueless in many circumstances. An example is asset covariance. Whilst I accept that there should be a factor which measures the benefits of diversification of asset types, past experience reveals many instances when different asset types exhibit sympathetic behaviour. Notwithstanding this comment, the development of any form of dynamic solvency testing will represent a vast improvement on the static formulae currently in use throughout the E.U.

I retain a problem with the assessment of the credit risk, defined by the authors in 94.3 .6 . The authors correctly assess that there is a credit risk arising from funds deposited at brokers and agents. They have also extended this section to cover reinsurance recoverables. In my opinion, reinsurance 
requires special consideration - in particular at Lloyd's (as planned) and the London Market. To date, many London Market companies can best be described as weakly capitalised, and they depend on their reinsurers for a major source of capital. Reinsurance, therefore, represents an asset of such companies and should be subject to similar assessment to other capital assets. In the future, I believe that the nature of reinsurance may change as more use is made of tradeable derivatives to provide the cash flows of companies at peaks of claims. Assessment of reinsurance as an asset recognises this explicitly, and would allow management and regulators to compare directly the relative riskiness of funding via reinsurance or other types of asset. Financial reinsurance, amongst the current cessions, should, in my opinion, be assessed alongside the companies' remaining assets.

Reserve risk is also likely to prove difficult to estimate purely from the historical data. The existence of IBNR catastrophes, such as the development of silicone implant claims over the recent past in U.S. casualty accounts, means that the assessment of this type of risk may not be possible mechanically. Further, such a calculation may well depend on a company's reserving philosophy, and how it compares to the rest of the market.

Capital and the return on capital employed are often used to assess the performance of many companies in all industries. The insurance industry, however, has not tried to assess clearly its capital needs and to examine its business proposition - underwriting on a return on capital employed basis. The questions of:

- how much capital is required;

- where is it held; and

- what return should be earned;

remain unanswered within our industry. The proposed approaches attempt to allocate capital by determining how capital should be constructed within any company. They are a good first attempt at the more fundamental question of - how much capital should an insurance company have to either continue in business for the foreseeable future or to run off its existing business over time?. These questions have been ignored to-date by the profession, and possible solutions must be found to them to allow management and supervisors to understand the dynamics of the insurance industry better. I agree with the authors and with the closer that a discussion of the underlying issues is likely to add the most value to the process. I also highlight that, in order to sign the necessary actuarial certificates for the Canadian assessment of solvency, some understanding of capital allocation is required. If such a certificate appears in the U.K., I think that recognition of these issues will become a matter of priority for most general insurance specialist actuaries and investment analysts.

The authors subsequently wrote: We were pleased that the paper generated a lively discussion. On reflection, however, we were a little disappointed that very little was said about the internal uses for capital allocation. Notable exceptions were the scepticism expressed by the opener and by Mr Smith. The closer, however, did indicate support for the development of this practical application, and we, ourselves, hope to see more work in this area.

The discussion certainly brought out many different perspectives that apply on the question of capital requirements. Some of the speakers concentrated solely on the shareholders' viewpoint, others on the policyholders' and supervisors' viewpoints, while others considered the management's viewpoint. This last viewpoint has to straddle and balance the different (and often conflicting) viewpoints of the other stakeholders. An appreciation of these different viewpoints leads to clearer understanding of who can diversify what risks, what risks cannot be diversified, and how (if at all) a given interested party can achieve diversification.

We were surprised that the existing E.U. solvency margin regime came in for relatively little criticism, especially in view of the historical background provided by the President. By comparison, the RBC formula that has been adopted in the U.S.A. is considerably more responsive, albeit more complex. While RBC is far from ideal, we see it as a step forward, giving a better 'approximation', as Professor Bühlmann described it, to the 'correct' method of dynamic financial analysis. We agree with the comments of Mr Nowell, that the U.S. formula has more merit than the comments of many speakers would suggest. We, therefore, would have liked to have heard some discussion of the 


\section{Risk-Based Capital in General Insurance}

practical steps that could be taken to overcome the political difficulties of changing the existing E.U. regime, alluded to by the President. We sympathise with the comments of Mr Wells, who raised the prospect of regulatory arbitrage, but we feel that capital requirements are unlikely to be the most critical aspect of this.

Professor Bühlmann brought into the discussion the relationship between profitability and capital requirements. Profitability is not static, however, and varies over the underwriting cycle. It is almost a prerequisite for the existence of the underwriting cycle that current profitability can never be known. Given this state of affairs, we find it difficult to see how profitability could be incorporated into a RBC formula for use across different market sectors. In this context, we would highlight $\mathrm{Mr}$ Czapiewski's point that the capital must be enough to see the company through the down cycle. This strengthens the case for dynamic financial analysis.

We expected more discussion of the Lloyd's RBC proposals, although these were (and still are) subject to debate and, perhaps, further development. Mr Newman made some interesting observations about whether it was really appropriate to give credit for diversification by class of business, as this may mean an underwriter venturing into unfamiliar territory. It is important to remember that the Lloyd's RBC proposals apply at the Name level rather than at the syndicate level. The credit for diversification by class of business, therefore, applies both within a syndicate and between syndicates, with further credits for managing agent diversification. Given the availability of these managing agent diversification credits, the Lloyd's proposed system will not necessarily encourage syndicates to diversify by class of business. Indeed, if diversification by class of business is done by individual syndicates, then Names might not achieve optimal credit, although this could depend on the relative size of the different credits available.

$\mathrm{Mr}$ Czapiewski wanted to see greater discrimination of the business, despite the further complexity that this would entail. Mr Craighead and others also commented on the difficulty of capturing more relevant exposure and accumulation information. We feel that these comments only serve to emphasise that any practical formula (including the existing E.U. solvency margin formula) will be a blunt instrument, and that supplementary methods will be needed for prudential supervision. We feel that more debate is needed about which factors should be included in such a formula, and about ways in which the interaction of these factors can be dealt with. We were disappointed that the discussion included few comments of this nature. We agree with Mr Nowell that more work is needed based on real data from the U.K. industry.

Several speakers thought that a statutory role for actuaries was highly desirable, and Mr Craighead indicated that the resources of the actuarial profession were now sufficient to take on this role. The inroads that actuaries are making (and, we believe, will continue to make) into many management aspects of non-life insurance entities suggest that a targeted statutory role could now be introduced. Mr Craighead indicated how difficult the task of the non-life Appointed Actuary would be. Our profession's readiness for this role could, perhaps, be made more transparent by further, open discussion of what such a role would entail. 